\author{
Economics Working Paper Series
}

2018/002

\title{
Preferential Trade Agreements and Antidumping Protection
}

Chrysostomos Tabakis and Maurizio Zanardi

The Department of Economics

Lancaster University Management School

Lancaster LA1 4YX

UK

(C) Authors

All rights reserved. Short sections of text, not to exceed two paragraphs, may be quoted without explicit permission, provided that full acknowledgement is given. 


\title{
Preferential Trade Agreements and Antidumping Protection*
}

\author{
Chrysostomos Tabakis \\ KDI School of Public Policy and Management \\ Maurizio Zanardi \\ Lancaster University Management School
}

January 2018

\begin{abstract}
Are preferential trade agreements (PTAs) stumbling blocks or building blocks towards multilateral trade liberalization? We address this question by investigating the effects of the negotiation and implementation of PTAs on the use of antidumping (AD) (i.e., the most common form of contingent trade protection) by member countries against non-members, as there has been a concurrent surge in regionalism and AD activity since the 1990s. Theoretically-derived empirical predictions are supported by the empirical analysis based on the 15 most intense users of $\mathrm{AD}$. The results demonstrate that both the negotiation and the implementation of PTAs lead to fewer AD measures against non-member countries, except for members of customs-union agreements in force facing large import surges from non-members. Thus, our results highlight a building-block effect of PTAs on multilateral trade cooperation when it comes to AD protection.
\end{abstract}

Keywords: Preferential trade agreements; antidumping; multilateral cooperation. JEL classification: F13; F14; F15.

\footnotetext{
${ }^{*}$ The authors would like to thank Haftom Teferi, Araya Mebrahtu Teka, and Luis Carlos Vargas Bolivar for excellent research assistance. The authors would also like to thank Xianwen Chen, Paola Conconi, James Lake, Mark Melatos, Emanuel Ornelas, Pascalis Raimondos, John Romalis, Keuk-Je Sung, and participants at an FIW Workshop (Vienna), a workshop of the Asia Global Institute (Hong Kong), the conference on the "Economics of Global Interactions" (Bari), the European Trade Study Group Conference (Florence), the Midwest International Trade Conference (Dallas), and seminars at KDI School of Public Policy and Management, Kyung Hee University Institute of International Studies, Queensland University of Technology, and the University of Sydney for very helpful comments and suggestions. Chrysostomos Tabakis gratefully acknowledges financial support from the KDI School of Public Policy and Management.

Corresponding author: Maurizio Zanardi: Lancaster University Management School, Department of Economics, Bailrigg, Lancaster LA1 4YX, United Kingdom. Telephone: +44-1524-593819. E-mail: m.zanardi@lancaster.ac.uk
} 


\section{Introduction}

The world has witnessed an astounding proliferation of preferential trade agreements (PTAs) since the early 1990s. According to the World Trade Organization (WTO), as of January 2018, the number of notified active PTAs stands at 284, with all WTO members being members of at least one PTA in force. ${ }^{1}$ And this figure is in fact likely to increase in the near future as many WTO members are currently involved in negotiations for new PTAs. The sheer number of such agreements has generated a large body of literature, started by Bhagwati (1991), analyzing whether PTAs are "building blocks" or "stumbling blocks" towards multilateral trade liberalization, which would be the first-best policy. ${ }^{2}$ A second major trend that has dominated international commercial policy over the same period is the dramatic increase in antidumping (AD) activity. Although the stated objective of $\mathrm{AD}$ is to eliminate the injurious effect of dumping (i.e., exporting a product at less than fair value), its application has nothing to do with maintaining a "fair" trading environment. AD "is simply a modern form of protection" (Blonigen and Prusa, 2003), which is nowadays used on a regular basis by a large number of developed and developing countries. ${ }^{3}$

Since AD measures can provide governments with a flexible trade policy instrument at a time when WTO commitments severely constrain the use of most-favored-nation (MFN) tariffs, it is natural to ask whether the building- or stumbling-block effect of PTAs might manifest itself (also) through the use of such measures. This natural question has not received much attention in the literature so far, although in his recent survey article on PTAs, Limão (2016) does point out that the interdependence of PTAs and non-tariff barriers against non-member countries is an important area for future research. This is the objective of this empirical paper, which aims to shed light on the ramifications of PTAs for their member countries' extra-PTA $\mathrm{AD}$ activity (i.e., the $\mathrm{AD}$ activity of PTA members against non-members).

A number of theoretical contributions have looked at whether PTAs help or hinder multilateral trade liberalization. However, the theoretical literature on this question remains largely

\footnotetext{
${ }^{1}$ See http://rtais.wto.org/UI/charts.aspx.

${ }^{2}$ See Freund and Ornelas (2010) and Limão (2016) for a survey of the literature on PTAs.

${ }^{3}$ Economists would agree that $\mathrm{AD}$ is justified in the case of predatory dumping, the objective of which is to drive out domestic producers from the home market for exporters to gain a dominant position in it, resulting in subsequent price increases. However, such predatory motives are absent in most AD cases, and the introduction of $\mathrm{AD}$ measures does not hinge upon them.
} 
inconclusive, as the answer depends on the modeling assumptions. This makes the empirical investigation of this issue all the more relevant. To guide our empirical strategy on the relationship between PTAs and AD, we rely on the theoretical work by Tabakis (2010, 2015). These papers explore the implications of the (symmetric) formation of, respectively, customs unions (CUs) and free-trade areas (FTAs) for contingent protection. Both papers employ a dynamic game of trade-policy setting, in which countries are limited to cooperative multilateral agreements that are self-enforcing - as is common in the literature - and the economic environment is characterized by exogenous trade-volume volatility. Restricting our attention to $\mathrm{AD}$ measures, which is the focus of our paper, three testable predictions emerge from Tabakis (2010, 2015): (i) the number of AD measures of members against non-members of an FTA agreement should decrease both during its negotiation and after its implementation; (ii) the number of AD measures of members against non-members of a CU agreement should decrease during its negotiation; and (iii) the number of $\mathrm{AD}$ measures of members against non-members of a CU agreement should increase following its implementation for "high" import volumes from non-member countries, whereas the reverse is true for "low" volumes of imports.

To empirically test these predictions, we carry out an extensive data collection process as we gather detailed data for a large number of PTAs. In particular, the testing of our predictions requires information on the dates of the launch of negotiations for the different PTAs in our sample and of their entry into force. Using then AD data over the period 1980-2015 and different econometric strategies, our results do provide clear support to the aforementioned theoretical predictions. Both the negotiation and the implementation of PTAs have a significant effect on the extent of AD use of PTA members vis-à-vis non-member countries. What is more important, PTAs generally have a dampening effect on their members' $\mathrm{AD}$ activity against the rest of the world, except when members of an implemented CU agreement face substantial import growth from non-member countries, which is in line with the theoretical predictions of Tabakis (2010). In brief, our results suggest that with one notable exception (i.e., CUs in force facing a substantial growth of extra-CU imports), PTAs are building blocks towards multilateral trade cooperation as far as AD protection is concerned.

Our paper contributes to the empirical literature on the ramifications of PTAs for multilateral trade liberalization, while focusing on non-tariff barriers. Some studies provide evidence 
in support of a building-block effect of PTAs (e.g., Estevadeordal et al., 2008), whereas others offer evidence showing that PTAs are stumbling blocks towards tariff liberalization at the multilateral level (e.g., Limão, 2006; Karacaovali and Limão, 2008). The paper by Estevadeordal et al. (2008), which also makes a distinction between FTAs and CUs, is probably the closest to ours (at least) as far as results are concerned. Their findings suggest that FTAs produce a building-block effect, while CUs lead to a considerably smaller reduction, if at all, in MFN tariffs than FTAs, which is very much in line with our findings. Our work complements these (and other) papers by highlighting that $\mathrm{AD}$ (i.e., the most important non-tariff barrier) represents a different channel through which PTAs affect multilateral trade cooperation. In other words, we demonstrate that in order to get a more thorough picture regarding the implications of regionalism for the multilateral trading system, other policy instruments besides MFN tariffs should be taken into consideration.

In relation to the interplay specifically between PTAs and AD use, only three papers (to the best of our knowledge) examine the empirical effects of PTAs on AD. Ahn and Shin (2011) look at the effects of FTAs on the intra-FTA AD filings of major AD users over 1995-2009, and find that FTAs inversely affect AD investigations within the boundary of FTA membership. In comparison, Silberberger and Stender (forthcoming) explore the impact of PTAs on the use of bilateral AD measures over the period 1991-2014, while explicitly considering the degree of intra-block tariff liberalization. They find that PTAs generally reduce the likelihood of AD activity among PTA members, but an improvement in the relative tariff treatment among fellow integration partners leads to a higher likelihood of bilateral AD activity than an equal improvement among non-integration trading partners. Finally, Prusa and Teh (2010), which is the paper closest in spirit to ours, investigate the ramifications of PTAs for both intraPTA AD filings and AD filings against non-member countries. They find that AD provisions in PTAs decrease the incidence of intra-PTA AD cases, but increase the number of filings against non-member countries. Postponing the discussion on the discrepancy between the latter result and our findings, it is important to stress at this point that our paper differs from these previous studies in two major respects. First, we distinguish between the negotiation and the implementation phases of PTAs. Second, we distinguish between FTAs and CUs. As the theoretical models by Tabakis (2010, 2015) suggest and our empirical analysis verifies, 
both distinctions are critical in order to get deeper insights into the ramifications of PTAs for $\mathrm{AD}$ protection.

The remainder of the paper is organized as follows. Section 2 provides a non-technical presentation of the theoretical framework that can be used to model the issues under investigation. The empirical predictions that follow from this framework and how they can be econometrically tested are discussed in Section 3. Section 4 is dedicated to the description of the data, with an emphasis on the extensive data collection undertaken to systematically record the history of formation (i.e., initiation of process, launch of negotiations, conclusion of negotiations, signature, ratification, and entry into force) of the PTAs in our sample. The empirical results are discussed in Section 5, together with a quantification of their implications for the use of $\mathrm{AD}$ and several robustness checks. Section 6 concludes.

\section{Theoretical Framework}

The main goal of this paper is to empirically examine the impact of PTAs on their members' extra-PTA AD activity (i.e., the AD activity of PTA members against non-member countries), thus shedding light on whether PTAs are building blocks or stumbling blocks towards multilateral trade liberalization. To this end, we rely on the theoretical work by Tabakis (2010, 2015) to derive testable predictions. Tabakis (2010) looks at the ramifications of symmetric CU formation for multilateral trade cooperation, while the companion paper, Tabakis (2015), focuses on FTAs.

The analysis in both papers rests on three main assumptions. First, as is common in the literature on trade agreements, countries are limited to self-enforcing multilateral agreements (i.e., agreements that balance for each country its short-term terms-of-trade gains from defection from the agreed-upon policies against the long-term welfare losses due to its trade partners' retaliation). ${ }^{4}$ Second, the economic environment is characterized by exogenous trade-volume volatility. As a result, "special" protection (or contingent protection-the two terms will be used interchangeably below) becomes an indispensable on-equilibrium-path safety

\footnotetext{
${ }^{4}$ See Bagwell and Staiger (2002) for an in-depth analysis of enforcement issues within the context of the GATT/WTO.
} 
valve, allowing countries to maintain multilateral cooperation amid volatile trade swings. More specifically, a trade agreement should allow countries to temporarily raise their cooperative level of protection - via using special protection - when facing significant import-volume surges so that their incentive to defect is kept in check and multilateral cooperation does not break down. ${ }^{5}$ Third, as in Bagwell and Staiger (1997a, b), the countries' trading relationship passes through three phases: an initial or pre-PTA-negotiations phase, a transition or PTAnegotiations phase with different PTAs being concurrently negotiated, and a final phase in which the PTAs in question are in force. In practice, the establishment of an FTA or CU entails a lengthy period over which an agreement is initially negotiated, subsequently ratified by all the member countries, and finally gradually implemented. ${ }^{6}$ In the earlier stages of this process, member and non-member countries face changes primarily with respect to expected future trade patterns rather than current ones, which implies that the relationship between regionalism and multilateral trade cooperation is non-stationary. Modeling therefore explicitly the PTA-negotiations phase is essential for a complete analysis of the ramifications of PTAs for the multilateral trading system over time.

Tabakis (2010) demonstrates, in the context of a competing-importers model, that the parallel initiation of different CU negotiations leads to an easing of multilateral trade tensions, especially with respect to the employment of special protection. Intuitively, this stems from the market-power effect of CU establishment due to the harmonization of the member countries' external trade policies. In particular, a CU, relative to any of its member states taken individually, enjoys more substantial market power (i.e., a greater ability to affect world prices) and can, therefore, credibly threaten to punish more harshly any deviation from the cooperative course. ${ }^{7}$ As a result, as countries enter (symmetrically) into CU talks and the establishment of different CUs becomes (more) likely, the expected discounted value of future multilateral cooperation increases. At the same time, countries' static gains from defection from the cooperative agreement remain unaffected as they are only a function of current trade

\footnotetext{
${ }^{5}$ See the seminal work by Bagwell and Staiger (1990) for further elaboration on this result. Bown and Crowley (2013) provide empirical evidence in support of this theoretical prediction.

${ }^{6}$ For the PTAs in force included in our benchmark analysis, almost 10 years passed on average between the launch of their negotiation and their entry into force.

${ }^{7}$ For empirical evidence that terms-of-trade or market-power considerations do play a significant role in trade policy formulation, see Broda et al. (2008) and Bagwell and Staiger (2011).
} 
patterns, upon which the mere initiation of CU talks has no effect. Thus, in comparison with the pre-CU-negotiations period, a more liberal multilateral trading environment is now feasible as countries are less inclined to revert to protectionist strategies, violating multilateral cooperation.

This beneficial effect of CU formation on multilateral cooperation is, however, temporary. Once the negotiations are over and the CU agreements come into force, countries' static incentive to deviate from the cooperative path also intensifies, and thereby, a more protectionist trading environment resurfaces. ${ }^{8}$ The reason is that the CUs can more effectively manipulate the terms of trade to their advantage than can any of their member countries when viewed in isolation. An important finding that emerges from the analysis of Tabakis (2010) is that in comparison with the pre-CU world (i.e., a world where there are no $\mathrm{CU}$ negotiations in the near horizon), the employment of contingent protection in the post-CU world is more severe for "high" import volumes, but is less frequent overall in the sense that a higher import-volume surge is required to warrant its use (on the equilibrium path).

These theoretical results are illustrated in Figure 1, which depicts the most cooperative level of protection $\left(\widehat{\tau}^{c}\right)$ than can be sustained multilaterally (i.e., between countries not part of the same $\mathrm{CU}$ in force) as a function of the free-trade import volume, which is subject to exogenous shocks. Notice that $\bar{e}$ refers to the critical import-volume threshold in a given period above which the employment of contingent protection becomes necessary so that multilateral cooperation does not break down. Considering the various phases the countries' trading relationship passes through, $\widehat{\tau}_{1}^{c}$ represents the (most cooperative) equilibrium tradeprotection function in the pre-CU world, while $\widehat{\tau}_{2}^{c}$ refers to the corresponding one during the CU-negotiations phase. As $\widehat{\tau}_{2}^{c}$ is to the right of and parallel to the original curve, this implies that above the threshold $\bar{e}_{1}$, the same level of imports will induce lower protectionist pressures (i.e., less contingent protection) once countries enter into CU talks. However, once the different CUs are implemented, the $\widehat{\tau}^{c}$ curve shifts to the left and becomes steeper (see $\widehat{\tau}_{3}^{c}$ ). Therefore, as compared with the pre-CU world, less (more) protectionist trade policies will be

\footnotetext{
${ }^{8}$ See Krugman (1991) for an early analysis of how CU formation might lead to a less liberal multilateral trading environment (in a non-cooperative setting). The major divergence of Tabakis (2010) from the (large) literature on the impact of CUs on the multilateral trading system is that he explicitly examines their ramifications for contingent protection.
} 
implemented at the multilateral level in the post-CU world for low (high) import volumes.

In his follow-up paper, Tabakis (2015) explores the implications of FTA agreements for special protection in the context of a model similar to the aforementioned one. He shows that the parallel formation of different FTAs leads to a gradual but permanent easing of trade tensions at the multilateral level, especially with regard to the use of special-protection instruments such as AD measures. The intuition underlying this finding is straightforward. The FTA agreements induce trade diversion, lowering the volume of trade between FTA partners and non-partner countries. This has a dampening effect on countries' static incentive to defect from the cooperative course, allowing for a less protectionist international trading environment to come forth. ${ }^{9}$ In fact, a relatively liberal environment can be maintained also during the FTA negotiations, as the prospective emergence of different FTAs with the accompanying reduction in multilateral trade barriers raises the expected discounted value of future cooperation, while leaving the short-term terms-of-trade gains from increased protection unaffected (as FTA negotiations have no effect on the existing trade patterns).

Again, these theoretical results can be illustrated in the same way as in the CU case. Figure 2 shows such a graphical representation of the results, where the $\widehat{\tau}^{c}$ curves are analogous to the ones in Figure 1. As in the CU scenario, $\widehat{\tau}_{2}^{c}$ lies to the right of $\widehat{\tau}_{1}^{c}$, but $\widehat{\tau}_{3}^{c}$ is now farther to the right and flatter than both $\widehat{\tau}_{1}^{c}$ and $\widehat{\tau}_{2}^{c}$. Thus, there is a gradual but continuous easing of protectionist pressures as countries negotiate and then implement different FTA agreements.

\section{Empirical Predictions and Methodology}

The theoretical framework described in the previous section leads to a number of testable predictions regarding the implications of the negotiation and implementation of PTAs for the use of contingent trade instruments. Among those that qualify as such, AD measures are the ones that are being used the most extensively around the world as they are relatively easy to administer, and a case for their introduction is not that difficult to meet the necessary

\footnotetext{
${ }^{9} \mathrm{~A}$ number of papers have demonstrated in different settings that FTA agreements might induce -after their implementation - their member countries to lower their tariffs vis-à-vis non-members (e.g., see Bagwell and Staiger, 1999; Bond et al., 2004; Ornelas, 2005). None of these papers though shares the focus of Tabakis (2015) on the implications of FTAs for contingent protection (rather, they restrict their attention to MFN tariffs).
} 
legal conditions. Countervailing duties and safeguards also fall in this category, but they are not used as extensively because of the more stringent conditions that must be fulfilled for introducing such measures. For example, Bown and Crowley (2016, Table 5) report several statistics related to the share of different countries' imports covered by contingent measures over the period 1995-2013. Their statistics demonstrate that AD is the favoured instrument and when countervailing duties and safeguards are used, they are often applied to the same products also targeted by AD. Moreover, among the countries included in our econometric analysis, it is only for China, the EU, Indonesia, Turkey, and the United States that other instruments besides $\mathrm{AD}$ have had a meaningful impact on trade, but even in these cases, only for some short time periods (see Table 5 and Figure 10 in Bown and Crowley, 2016).

Thinking of AD measures as the instrument of contingent protection, the theoretical models by Tabakis $(2010,2015)$ lead to the following testable predictions:

1. The number of AD measures of members against non-members of an FTA agreement should decrease both during its negotiation and after its implementation;

2. The number of AD measures of members against non-members of a CU agreement should decrease during its negotiation;

3. The number of $\mathrm{AD}$ measures of members against non-members of a $\mathrm{CU}$ agreement should decrease (increase) following its implementation for low (high) import volumes from non-member countries.

In order to assess these predictions, we proceed in two steps. First, we evaluate whether the negotiation and the implementation of PTAs affect the use of AD measures by PTA members against non-member countries, without distinguishing between FTAs and CUs. This serves as a preliminary stage to find out whether there is any prima facie evidence in the data of the effects that should manifest themselves as a result of the establishment of PTAs. Notice that a lack of evidence on PTA implementation affecting AD use may be due to the opposite effects that FTA and CU agreements might produce once implemented (as a function of member countries' import volume from non-member countries). On the other hand, the negotiation of PTAs is unambiguously expected to have a negative impact on their (prospective) members' 
extra-PTA AD activity since during the negotiation of either an FTA or a CU agreement, the negotiating countries should engage in less AD activity against the rest of the world as compared with the pre-negotiations period. In the second step, the three predictions are individually tested by considering the differential effects of FTA and CU agreements on the employment of $\mathrm{AD}$ protection, especially after their entry into force.

In both steps, the dependent variable $\left(A D_{i, j, t}\right)$ is the count of new $\mathrm{AD}$ measures imposed by country $i$ against country $j$ in year $t$. Given that the dependent variable is a non-negative integer, we employ a negative binomial estimator for all of our regressions. ${ }^{10}$ The basic specification we estimate in the first step is

$$
\begin{gathered}
A D_{i, j, t}=\beta_{1} \text { PTAs negotiation } \text { ni,k,t }+\beta_{2} \text { PTAs } \text { implemented }_{i, k, t}+ \\
\beta_{3} X_{i, j, t-s}+\beta_{4} Z_{i, t-s}+\beta_{5} W_{j, t-s}+\phi_{t}+\mu_{i}+\nu_{j}+\varepsilon_{i, j, t}
\end{gathered}
$$

where PTAs negotiation ${ }_{i, k, t}$ and PT As implemented $_{i, k, t}$ are our regressors of interest. PT As negotiation $_{i, k, t}$ is the count of PTAs that country $i$ is negotiating with any country $k \neq j$ at time $t$, while PTAs implemented ${ }_{i, k, t}$ counts the number of implemented PTAs (i.e., PTAs in force) between countries $i$ and $k \neq j$ in year $t$ (out of those that have entered into force during the sample period). Notice that the important feature of these variables is that they measure the involvement of country $i$ in PTAs not including the trade partner $j$, as the focus of our analysis is on the effect of PTAs on AD use between their members and non-member countries. In terms of other variables, we control for the level of bilateral imports of country $i$ from country $j$, their growth, and the bilateral real exchange rate (all part of $X_{i, j, t-s}$ ), as well as for the GDP growth of importing country $i\left(Z_{i, t-s}\right)$ and exporting country $j\left(W_{j, t-s}\right) .{ }^{11}$ Year fixed effects (i.e., $\phi_{t}$ ) are always included, while $\mu_{i}$ and $\nu_{j}$ represent separate importer and exporter fixed effects; alternatively, $\mu_{i}$ and $\nu_{j}$ are replaced in some specifications by countrypair (i.e., dyad) fixed effects. Standard errors are always clustered at the country-pair level, although we discuss alternative possibilities in the robustness section.

In the second step of the econometric analysis, we distinguish the effects of the negotiation and the implementation of FTAs from the corresponding effects associated with CU forma-

\footnotetext{
${ }^{10}$ Compared with the Poisson estimator that assumes that the mean and the variance of the dependent variable are the same, the negative binomial allows for overdispersion (i.e., a larger variance), which is what we observe in our data.

${ }^{11}$ The subscript $s$ indicates different lags of the regressors.
} 
tion. Thus, our key regressors are four in those estimations: FTAs negotiation ${ }_{i, k, t}$, FTAs implemented $_{i, k, t}, C U s$ negotiation $_{i, k, t}, C U$ s $_{\text {implemented }}, k, t$. Furthermore, the specification must allow for differential effects between FTA and CU agreements following their implementation as a function of the import volume of member countries from non-members. Thus, the implementation regressors need to be interacted with Import growt $_{i, j, t / t-1}$ to verify whether the data confirm that extra-CU AD activity may actually increase as a result of the implementation of a successfully negotiated CU agreement and a surge in CU members' imports from non-member countries.

The possible effects of the negotiation and implementation of PTAs on their members' extra-PTA AD activity are identified through different variation in the data, depending on whether importer and exporter or dyad fixed effects are used. The use of country-pair fixed effects makes for the most demanding specification, as any time-invariant country-pair heterogeneity is absorbed by the dyad fixed effects, and any significance of the coefficients of interest stems from variation within the country pairs due to the different PTAs in which the importing countries are involved over time (in terms of negotiation and implementation). If this is the cleanest identification method in controlling for any unobservable (non-time-varying) country-pair $\mathrm{AD}$ determinant, the non-linear nature of the estimator forces us to drop any country pair $(i, j)$ for which it is the case that not a single AD measure has been introduced by the importing country $i$ against the trade partner $j$ during the sample period. Some of these country pairs should be dropped from the estimation because they are such that AD measures are highly unlikely (e.g., very small exporting country). However, country pairs may be excluded when a zero for $\mathrm{AD}$ measures is a "true" zero: $\mathrm{AD}$ measures happen to be zero but they could have occurred. Using separate importer and exporter fixed effects represents an alternative identification strategy, which does not exclude these observations. In this case, only importing countries that have used $\mathrm{AD}$ at some point during the sample period (against any trade partner) are included, but this is not a limitation since we do want to restrict the analysis to active and intense users of $\mathrm{AD}$.

When including dyad fixed effects, these effects are estimated instead of relying on a conditional fixed-effects estimator. In the latter case, a conditional likelihood function is used so that the effects are "conditioned out" of the likelihood function and do not need 
to be estimated. Thus, this estimator is not equivalent to what is usually thought of as a fixed-effects estimator (i.e., there are no different intercepts). In fact, the coefficients of timeinvariant variables can be identified in conditional fixed-effects estimations. On the other hand, the inclusion and estimation of dyad fixed effects may give rise to inconsistent estimates due to the incidental parameter problem in short panels. However, Allison and Waterman (2002) demonstrate that no such bias emerges. ${ }^{12}$

Before moving to discussing the data and the results, a few observations are in order. First of all, our key regressors (i.e., the ones related to negotiation and implementation of PTAs by importer $i$ ) only take into consideration PTAs affecting at least a minimum level of country $i$ 's imports in the year before their entry into force, or if not yet in force by the end of our sample period, in the year before the launch of their negotiation. As a matter of fact, we can reasonably expect that the mechanisms discussed in Section 2 are at play only if a PTA affects a significant amount of member countries' trade, else the trade-diversion and market-power effects underlying the economic forces at work would not manifest themselves. Theory is silent on what "significant" actually means in practice. In the benchmark regressions, we assume this import-share threshold to be $10 \%$, but we discuss the sensitivity of our results to the chosen threshold in the robustness section. ${ }^{13}$

In terms of the sample, we do not include country pairs that are partners to a PTA in force or are involved in the negotiation of one. In fact, our focus is on verifying whether PTAs have an effect on the use of $\mathrm{AD}$ measures by their members against non-member countries while being negotiated and after entering into force. Our empirical analysis thereby focuses on a comparison of $\mathrm{AD}$ patterns between members of PTAs and non-members before versus after the negotiation and the implementation of the PTAs in question, not on a comparison of AD patterns within PTAs vis-à-vis AD patterns between PTA members and non-member countries (although we revisit this choice in the section on robustness checks). ${ }^{14}$

\footnotetext{
${ }^{12}$ In addition, for some country pairs, our sample covers a period of 36 years (see Table A2 in the Appendix).

${ }^{13}$ As expected, the effects become less precisely estimated when using lower thresholds.

${ }^{14}$ We exclude any pair of countries that are members of the same PTA in force as recorded by de Sousa (2012). In the case of a country pair $(i, j)$ negotiating a PTA, we exclude it if the share of imports of country $i$ affected by the trade agreement is at least $1 \%$.
} 


\section{Data}

In order to implement the econometric strategy discussed in the previous section, three sets of data are needed. Comprehensive details on the history of formation of existing PTAs are the first cornerstone and the data that proved the most difficult to collect. Data on the use of AD are required to construct the dependent variable, while trade and macro variables constitute the final set of data. In the following, we discuss each of these datasets in turn.

Regarding PTAs, our full sample includes all agreements notified to the GATT/WTO that satisfy all of the following three conditions: (i) they have entered into force from 1980 (i.e., the first year of our sample period) onwards and were still active by the end of 2015 (i.e., the last year of our sample period), or they were not yet in force by the end of the sample period but their negotiation has been announced "early" to the WTO; (ii) they involve at least one of the 15 most intense users of $\mathrm{AD}$ (to be defined below); and (iii) they affect, for their member countries identified by condition (ii), at least $1 \%$ of their imports in the year before entering into force, or for PTAs still under negotiation by the end of 2015, in the year before the launch of their negotiation. For these PTAs, we carried out an extensive data collection process since no single source (e.g., Dür et al., 2014) provides complete details on the history of formation of the existing PTAs. In particular, for each PTA in our sample, we gathered the dates of the initiation of the PTA formation process (e.g., the launch of a joint feasibility study or the expression of intention to explore the possibility of a PTA), the (announcement of the) launch of negotiations, the actual start of negotiations (i.e., the beginning of the first round of formal negotiations), the formal conclusion of negotiations, the signature of the agreement, the ratification of the agreement, and the entry into force of the agreement, with our empirical analysis focusing on the launch of negotiations for the different PTAs and their entry into force. ${ }^{15}$ The information comes from a wide range of online sources, including (but not limited to) the WTO, the European Commission, the European Parliament, the Office of the United States Trade Representative, the Foreign Trade Information System (SICE) of the

\footnotetext{
${ }^{15}$ In some cases (e.g., the EU-South Africa Trade, Development and Cooperation Agreement) an agreement is provisionally applied before it fully enters into force. For these agreements, we use in our empirical analysis the date of provisional application rather than the date of entry into force, as the provisional application of a PTA already has important ramifications for the trading relationship between its members and non-member countries (e.g., in terms of trade diversion).
} 
Organization of American States, the Asia Regional Integration Center (ARIC) of the Asian Development Bank, partner countries' official sources (e.g., the Ministry of Foreign Affairs of South Korea or the Ministry of Commerce of China), or national legislative bodies (for ratification dates). As a last resort, we also used historical data from quality newspapers.

Using $10 \%$ as the import-share threshold in condition (iii) above in order to choose which PTAs to include in our benchmark analysis, we end up with 24 PTAs for the construction of our key regressors related to negotiation and implementation of PTAs by importer $i$ (see Table A1 in the Appendix for the full list). Out of these 24 PTAs, four are classified as still under negotiation based on their status at the end of the sample period, while only four are CUs. It is important to notice here that one given PTA may be counted for more than one of the importing countries included in the analysis depending on members' intra-PTA import share. For example, NAFTA is counted for all three member countries-i.e., Canada, Mexico, and the United States - but the CU between the EU and Turkey is counted only for Turkey due to EU imports from Turkey in 1995 (i.e., the year before entry into force of the agreement) representing less that $10 \%$ of the EU's total imports. Moreover, it should be stressed here that there are few CUs in the sample which, if anything, may make it harder to identify the CU effects predicted by our theoretical framework.

Data on the worldwide usage of AD (since 1980) come mainly from the Global Antidumping Database (Bown, 2015) and are complemented by data from Moore and Zanardi (2009) for some countries and years. ${ }^{16}$ In particular, these sources allow us to construct the dependent variable, $A D_{i, j, t}$, as the count of $\mathrm{AD}$ measures introduced by an importer $i$ against an exporter $j$ in year $t$. Since we would expect the PTA effects on the use of AD to occur only for those countries that do make systematic use of this form of contingent protection, we limit the sample of importing countries to those using intensely this policy instrument. Table 1 provides several summary statistics on the worldwide use of AD (i.e., initiations and measures) over our sample period, which runs from 1980 until 2015 with a later starting year for importing countries that have implemented an AD law more recently (see Table A2 in the Appendix for details on included years by country). In order to select which countries to include in our sample

\footnotetext{
${ }^{16}$ For the sample used in the econometric analysis, only the data for Canada before 1995, the EU before 1987 and New Zealand before 1995 are taken from Moore and Zanardi (2009).
} 
of importers, we consider the cumulative number and annual average of AD investigations and applied measures (e.g., duties, price undertakings) by country. ${ }^{17}$ The summary statistics reported in Table 1 confirm previous findings in the literature in terms of the countries that are the most intense users of this instrument. Based on the table, we include in our sample of importing countries the five usual traditional users of AD (i.e., Australia, Canada, the EU, New Zealand, and the United States) and the ten most active new users: Argentina, Brazil, China, India, Indonesia, Mexico, Peru, South Africa, South Korea, and Turkey. We choose to include New Zealand among them because, although its numbers of initiations and measures per year over our entire sample period are not very large, it was a heavy AD user in the 1980s (a period which is included in our analysis); and in a robustness check, we drop it. ${ }^{18}$

As for the import data (at the aggregate bilateral level), they are taken from the IMF Direction of Trade Statistics (DOTS) and they serve two purposes. First, we need to control for the size of imports from a given trade partner and their growth as they are both known determinants of $\mathrm{AD}$ measures against the country in question. Not less importantly, one of the empirical predictions emerging from Tabakis (2010) is that the effect of CU agreements once implemented on the $\mathrm{AD}$ usage of their members against non-member countries depends on the members' import volume from the latter. Hence, interacting import growth (between $t$ and $t-1$ ) with the PTA implementation variables is key in distinguishing the impact of FTAs from CUs on their members' extra-PTA AD activity.

Finally, macro controls comprising the (log of the) bilateral real exchange rate (with a 1-year lag) and importer and exporter GDP growth rates (between $t$ and $t-3$ ) are included as they have been shown to affect the introduction of AD measures (e.g., see the seminal work by Knetter and Prusa, 2003). In fact, the lag structure we employ for the macro controls is identical to the one of Knetter and Prusa (2003). Our macro variables are taken from the World Development Indicators (WDI).

Merging these three sets of data, the sample consists of 15 importing countries and all of their trade partners as exporters over the period 1980-2015. Notice though that starting

\footnotetext{
${ }^{17}$ Initiations and measures per year are based on the number of years for which a country has had an AD law in force during the sample period 1980-2015.

${ }^{18}$ We do not include Taiwan in our sample of importers, even though it has initiated several investigations, because of its very low success rate for the introduction of measures (i.e., $23.4 \%$ versus $56.1 \%$ for the entire set of $\mathrm{AD}$ users and $57.1 \%$ for the chosen 15 importers), which we use as our dependent variable.
} 
from the consideration of all potential trade partners of the 15 importing countries identified above, import and macro data are missing in many cases, and therefore, the inclusion of the associated regressors forces us to drop many observations. For the observations included in the set of regressions with all the controls, the summary statistics of our variables are reported in Table 2. It is clear that $\mathrm{AD}$ measures are not very common, even though they are very important policywise (and the $A D_{i, j, t}$ average doubles in the sample used in the regressions with dyad fixed effects, consisting of country pairs with at least one AD measure). In terms of the key regressors of interest, the maximum number of either simultaneous PTA negotiations or simultaneous PTA implementations is 5, which is reached in both cases by Indonesia because it is part of the agreements involving ASEAN (see Table A1). Moreover, the summary statistics of our FTA and CU regressors clearly illustrate that there are few CUs in our sample (especially under negotiation), which could make it difficult to uncover in the data the theoretical results discussed in Section 2.

\section{$5 \quad$ Empirical Results}

The results of the first step of our estimation strategy are presented in Table 3. In this case, we do not distinguish between FTAs and CUs in their effects on the use of AD by their members against the rest of the world. Still, it should be the case that higher values of PTAs negotiation $i, k, t$ lead to fewer extra-PTA AD measures (i.e., the effects of FTA and $\mathrm{CU}$ agreements during their negotiation are the same). In addition, the estimated coefficient for PTAs implemented ${ }_{i, k, t}$ should also be negative, except if the effect from members of CUs facing high import growth from non-member countries dominates.

Table 3 includes eight specifications that differ because of fixed effects, of whether control variables are included or not, and of the functional form of PTAs negotiation ${ }_{i, k, t}$ and PTAs implemented $_{i, k, t}$ (in logs in the last four columns). Even before discussing the differences between these modeling strategies, it is obvious that the results are quite robust: the negotiation and the implementation of PTAs between an importing country $i$ and any country $k \neq j$ in year $t$ both reduce the number of $\mathrm{AD}$ measures that country $i$ introduces against trading partner $j$ in the same year. All but one of the relevant coefficients are statically significant 
at the $1 \%$ level and they are larger (in absolute terms) for implemented PTAs than for PTAs under negotiation. Thus, it is the case that the data provide broad support for the theoretical predictions discussed in Section 2. In graphical terms, the negative coefficients for PTAs negotiation $_{i, k, t}$ represent the downward shift in the $\widehat{\tau}^{c}$ curve between phases 1 and 2 in both Figures 1 and 2, since as different PTA negotiations are launched, countries' expected value of future multilateral trade cooperation increases, while their static incentive to defect from the cooperative course remains unaffected. Regarding the coefficients for PT As implemented $_{i, k, t}$, Figures 1 and 2 highlight an important difference between FTA and CU agreements following their implementation that we will address in the following table (i.e., Table 4).

Looking in detail at the results in Table 3, the first specification includes only year, importer and exporter fixed effects together with the key regressors of interest. It is clearly the case that this minimalist version should be augmented by the inclusion of the trade and macro controls that the literature has shown to be important determinants of AD activity. Although their inclusion in column (2) forces us to drop many observations due to missing data, it is reassuring to see that reducing the sample size has minimal effects on the estimated coefficients. As far as the control variables are concerned, their coefficients are in line with what we expect from previous studies: the estimated coefficients for import volume and import growth are positive (although the latter is not statistically significant), as is the case for the coefficient of the bilateral real exchange rate (while importer and exporter GDP growth rates are not statistically significant). ${ }^{19}$ Columns (3) and (4) are analogous to the first two columns, but they are based on specifications including dyad fixed effects. This strategy entails a significant loss of observations also for the minimalist specification (i.e., any country pair $(i, j)$ for which it is the case that not a single $\mathrm{AD}$ measure has been introduced by the importing country $i$ against the trade partner $j$ during the sample period is dropped), resulting in a smaller drop in observations when the controls are included. Still, the results are very similar to the previous ones: there are no significant differences between the estimates in columns (2) and (4).

The last remaining four columns re-estimate the same specifications with the key regressors

\footnotetext{
${ }^{19}$ Notice that a higher value of the bilateral real exchange rate variable corresponds to an appreciation of the real exchange rate of the importing country.
} 
PTAs negotiation ${ }_{i, k, t}$ and PT As implemented ${ }_{i, k, t}$ replaced by the log of one plus these count variables. This alternative formulation imposes a non-linear effect of the negotiation and implementation of PTAs on their members' extra-PTA AD activity and the results confirm this to be the case. Furthermore, the reduction in the sample size in columns (6) and (8) due to the inclusion of the control variables does not change our qualitative conclusions.

The dual purpose of Table 3 was to establish prima facie evidence of the effects predicted by our theoretical framework and to dispel any concern of sample selection bias due to the unavailability of the trade and macro controls. The latter is crucial as we move to the second step of our analysis, where the inclusion of import growth is essential in order to test the empirical predictions in all of their details. The results of the second step are reported in Table 4, which does not include any minimalist specification since import growth is more than just a control variable and cannot be excluded. Columns (1) and (3) employ year, importer and exporter fixed effects, while columns (2) and (4) use year and dyad fixed effects. As for the functional form of the count of PTAs under negotiation and in force, in the last two columns we use their log version.

The results in Table 4 demonstrate that the negotiation of PTAs reduces (prospective) members' extra-PTA AD activity with a stronger (in terms of significance and magnitude) dampening effect for $\mathrm{CU}$ agreements. As far as PTAs in force are concerned, FTAs have a negative effect on the employment of $\mathrm{AD}$ protection independently of the growth of extra-FTA imports. The implementation of $\mathrm{CU}$ agreements has an overall negative impact too on their members' $\mathrm{AD}$ activity against the rest of the world, but the interaction term with import growth is positive and significant across all specifications, which indicates that this beneficial effect of $\mathrm{CU}$ establishment (from a cooperative perspective) may be overturned when $\mathrm{CU}$ members face sufficiently large import surges from non-member countries. This last result is consistent with the empirical predictions derived from Tabakis (2010) and especially with the slope of the $\widehat{\tau}_{3}^{c}$ curve in Figure 1. As for the other regressors, their coefficients' significance is very much in line with the results of Table 3 . Notice that some of the coefficients are imprecisely estimated when using the log version of the key regressors in the last two columns. As a matter of fact, regarding CUs, there may not be enough variation in the data to uncover a non-linear effect for their implementation given that most of our PTAs take the form of 
FTAs and $C U$ s $_{\text {implemented }}, k, t$ takes at most the value of $2 .{ }^{20}$

Notice that these results seem to be at odds with the findings of Prusa and Teh (2010) who showed that PTAs tend to increase the incidence of AD filings by PTA members against non-member countries. However, a comparison between the PTAs included in our analysis and those included in theirs reveals a very limited overlap, which also implies that the sample of importing countries used in their analysis is quite different from ours. This important observation together with a different econometric methodology can explain the apparent contradiction between the two studies. Interestingly, the aforementioned effect of PTAs against non-members seems to hold only when considering the subset of PTAs with AD rules regulating intra-PTA AD activity (e.g., see their Table 7).

In conclusion, the estimates of Tables 3 and 4 provide clear support for the theoretical predictions discussed in Section 2, suggesting that PTAs mostly constitute a building block towards further multilateral trade liberalization. In particular, the negotiation and the implementation of PTAs both have an effect on the extent of AD use by PTA members against non-member countries. The more interesting part is that in both cases, the mechanisms at play (underlain by the market-power and trade-diversion effects of PTAs) induce a lower extraPTA AD activity, except when members of CUs in force face substantial import growth from non-member countries. And this differential effect between FTAs and CUs on the multilateral trading system is very much in line with the evidence provided by Estevadeordal et al. (2008).

\subsection{Quantification of Effects}

Given the non-linear nature of the estimator, the estimated coefficients do not allow for a quantifiable interpretation of the impact of our key regressors on $\mathrm{AD}$ patterns. To facilitate such an analysis, we report in Tables 5 and 6 the predicted counts of AD measures based on our estimations, focusing on the specifications including dyad fixed effects, which are the most demanding in identifying the ramifications of PTAs for AD.

For the specifications in columns (4) and (8) of Table 3, Table 5 reports the predicted

\footnotetext{
${ }^{20}$ The significance of the coefficients of the key regressors would improve if we were to exclude Indonesia as an importing country. Indonesia is the country with both the most negotiations and the most implementations of FTAs - 5 in both cases - because of its membership in ASEAN (see Table A1 in the Appendix).
} 
counts of $\mathrm{AD}$ measures when an importing country is not involved in either the negotiation or the implementation of any PTA versus when an importing country is involved in the negotiation and/or implementation of one PTA. ${ }^{21}$ Clearly, AD is a relatively rare phenomenon (as already seen in the summary statistics in Table 2) even when restricting the sample to country pairs with at least one AD measure during the sample period (i.e., when including dyad fixed effects): the estimates predict fewer than one AD measure when there is no PTA either under negotiation or in force (i.e., 0.470 or 0.441 , depending on the specification). The relevant question, though, is what happens to these country pairs when an importing country is involved in the negotiation and/or implementation of a PTA. The predicted count of AD measures then drops significantly: based on column (1) of Table 5, one PTA under negotiation (implemented) reduces the count of $\mathrm{AD}$ measures by $25 \%$ (34\%), with an overall reduction of $50 \%$ for importing countries simultaneously negotiating and implementing PTAs. ${ }^{22}$ The magnitudes in column (2), based on the specification with the log version of our main regressors, are quite similar in size (implying a 23\%,33\%, and $49 \%$ drop in the predicted count of $\mathrm{AD}$ measures, correspondingly). ${ }^{23}$ These changes in the predicted count of $\mathrm{AD}$ measures by importer $i$ against exporter $j$ are quite large, but we must keep in mind that they are based on PTAs that affect at least $10 \%$ of the import volume of the importing country in question.

Table 6 reports similar calculations for columns (2) and (4) of Table 4 where we distinguish between FTA and CU agreements and also include interaction terms between the implementation regressors and import growth. As a result, Table 6 is more cumbersome to read as the effect of implemented FTA or CU agreements must be evaluated at different values of import growth. Still, the picture that emerges from Table 6 is qualitatively similar to the one from Table 5: the negotiation and the implementation of FTA and CU agreements all have a significant impact on the number of extra-PTA AD measures that their members introduce, with the dampening effect for implemented $\mathrm{CU}$ agreements being mitigated when $\mathrm{CU}$

\footnotetext{
${ }^{21}$ Similar counts can be computed for more than one PTA under negotiation and/or in force, but they would not add much to the interpretation of the results.

${ }^{22}$ The estimated counts within each column of Table 5 are statistically different from one another except for the second and third counts for each specification (i.e., the effects of being involved in the negotiation or the implementation of one PTA are not statistically different from each other).

${ }^{23}$ The two specifications would give rise to more significantly different counts if we were to compute counts for more than one PTA under negotiation and/or in force, as in that case the log transformation would play a bigger role.
} 
members face large import surges from non-member countries. Focusing without loss of generality on column (1), all the predicted counts associated with FTAs are statistically different from one another (at least at the $5 \%$ level), except for the counts calculated for the same FTA-involvement status but at different percentiles of import growth. In other words, and as predicted by the theory, the implementation of an FTA agreement has a negative effect on members' extra-FTA AD activity, and this effect does not depend on extra-FTA imports (i.e., 0.249 is not statistically different from 0.264 , and in the same way, 0.214 is not statistically different from 0.226). Considering CUs, their negotiation significantly reduces the predicted count of $\mathrm{AD}$ measures (it drops from 0.359 to 0.183 ), but import growth does matter when it comes to quantifying the effects of implemented CU agreements. For example, one implemented CU agreement along with low import growth from non-members lead to fewer $\mathrm{AD}$ measures against them than no implemented CU agreement at all (i.e., 0.359 is statistically different from 0.249), but there is no discernible effect when CU members' import growth from non-members is high (i.e., 0.359 is not statistically different from 0.287 ). Thus, in the latter case, the building-block effect of CUs is eliminated, but still there is no evidence of CUs being stumbling blocks towards further multilateral trade liberalization. The estimated counts in column (2) provide a very similar picture.

In conclusion, it is not only the estimated coefficients that provide evidence in support of the theoretical predictions discussed in Section 2. The quantification exercise demonstrates that the building-block effect of PTAs is sizable but can disappear in the case of implemented CU agreements and large (enough) surges of extra-CU imports.

\subsection{Robustness Checks}

Tables 3 and 4 already include various robustness checks and demonstrate that our results are robust to different modeling choices. They address the issue of sample selection due to data availability, they rely on different econometric strategies (i.e., sets of fixed effects), and they consider different functional forms for the count variables related to the negotiation and implementation of PTAs. However, all the results presented so far are based on PTAs that affect at least $10 \%$ of the import volume of the importing country under consideration (in the year before entering into force, or in the year before the launch of negotiations for agreements 
not yet in force by the end of 2015). The choice of a threshold of $10 \%$ is based on the interest to consider PTAs that can be expected to have meaningful trade effects that would affect their members' gains from multilateral cooperation and defection from the cooperative course. Still, the $10 \%$ threshold is simply assumed and we need to verify whether the results are sensitive to our threshold choice.

Thus, we re-estimate our specifications using a threshold of $5 \%$. In such case, we would expect the results to become weaker in terms of economic significance and probably less statistically significant as "smaller" PTAs are now included. ${ }^{24}$ Table 7 presents the results of such an exercise, only reporting estimates based on the use of dyad fixed effects, as their inclusion leads to the most demanding of the specifications. The first two columns parallel columns (4) and (8) of Table 3, with the second column employing the log version of the PTA count variables; the remaining two columns mirror columns (2) and (4) of Table 4, again with the linear and non-linear formulation of the key regressors. Overall, the results are very much in line with our previous conclusions although the main regressors of interest sometimes present smaller coefficients (in absolute terms) and/or lower levels of significance (while the coefficients for the control variables do not present any substantial change). The only significant change is that the coefficient for FTAs negotiation ${ }_{i, k, t}$ is not significant even when employing the linear version of the variable. ${ }^{25}$

Furthermore, an alternative way to capture the importance trade-wise of the different PTAs for their members would be to use as regressors the shares of trade affected by the negotiation and implementation of PTAs. In that case, we would not have to choose a threshold at all, but different complications would arise. On a methodological front, we may be concerned that such shares are endogenous to the use of $\mathrm{AD}$. On a conceptual front, enlargements of the EU create problems since we consider the EU as a "country" and do not count its internal trade, which poses difficulties for the trade-share calculations once an EU enlargement agreement is implemented. ${ }^{26}$ For these reasons, such an exercise proves very problematic. Still, if we were

\footnotetext{
${ }^{24}$ With a 5\% threshold, 12 more PTAs, of which one is a CU, are used to compute our main regressors of interest.

${ }^{25}$ If we were to reduce the threshold even further to $1 \%$, the estimated coefficients of the key regressors would also be smaller (in absolute terms) and somewhat less significant but the main qualitative results would survive. The only major difference compared with Table 7 would be that the coefficient for the interaction of implemented FTAs and import growth would be positive and statistically significant in column (4).

${ }^{26}$ For example, EU trade with Poland is included in the total trade of the EU during the enlargement
} 
to ignore the endogeneity problem and drop the EU from the sample of importing countries, the results would be qualitatively in line with what we have presented so far: the higher the shares of trade affected by the negotiation and the implementation of PTAs, the fewer extra-PTA AD measures an importing country introduces. ${ }^{27}$

In another methodological check, we re-estimate our results without excluding the country pairs that are partners to a PTA in force or are negotiating one. At the end of Section 3, we argued that these observations should be excluded since the focus of the paper lies on examining the effect of PTAs on their members' extra-PTA AD activity, in order to ascertain whether PTAs constitute a building block or a stumbling block towards further multilateral trade liberalization. In addition, the theoretical models by Tabakis (2010, 2015) only lead to empirical predictions on the pattern of AD between PTA members and non-member countries. Still, we can include the observations so far discarded, remaining agnostic on how the negotiation and the implementation of PTAs affect their members' intra-PTA AD activity. Table 8 presents the same type of specifications as in Table 7 with these extra observations (almost 3,000) and dummy variables that control for country pairs that are members of the same PTA (PTA dummy du $\left._{i, j}\right)$ or are negotiating a PTA (Negotiation dummy $\left.{ }_{i, j, t}\right)$. The results show that the conclusions we reached earlier are overall still valid (although the results are weaker for the negotiation of FTAs and the implementation of CUs). Moreover, our results are consistent with the findings of Prusa and Teh (2010), Ahn and Shin (2011), and Silberberger and Stender (forthcoming) that PTAs have a dampening effect on the AD activity between their member countries. Instead, the estimated coefficient for Negotiation dummy $y_{i, j, t}$ is never significant.

We can also experiment by changing the set of importing countries included in the analysis. $^{28}$ We start by dropping New Zealand as it was a heavy user of AD in the 1980s, but has ever since dramatically decreased the use of AD measures. Excluding New Zealand as an importer does not affect any of our qualitative conclusions. Considering the predominant role that India and China have been playing recently when it comes to $\mathrm{AD}$, it is reassuring that

negotiations. Once Poland becomes though a member of the EU, its trade flows with the other EU countries are not counted as part of EU trade.

${ }^{27}$ Considering the limitations of this exercise, we do not report these results, but they are available upon request.

${ }^{28}$ These robustness checks are omitted to save on space but are available upon request. 
our results are qualitatively unchanged as well when we drop them from the list of importing countries.

In a final set of methodological checks (not reported to save on space), we first drop year fixed effects and replace our importer or dyad fixed effects with the interaction of such fixed effects and a trend (i.e., we allow for importer or dyad-specific trend fixed effects). Such a change would address the concern that countries have become overall more open to trade over time, translating in both an increase in the negotiation and implementation of PTAs and a reduction in the use of AD. Once again, our qualitative results are unchanged by the use of these different fixed effects. Finally, we have also tried clustering standard errors at the importer-year level, in consideration of the fact that the number of PTAs under negotiation and in force varies only by importer and year. Even though the standard errors increase, the statistical significance of our key regressors is almost unchanged except for FTAs negotiation $_{i, k, t}$ in the first two columns of Table 4 that loses its significance. ${ }^{29}$

\section{Conclusions}

This paper has empirically explored the implications of PTAs for their member countries' extra-PTA AD actions (i.e., the AD measures of members against non-member countries). In so doing, it contributes to the long literature examining whether PTAs are building blocks or stumbling blocks on the road to further multilateral trade liberalization. To guide the econometric analysis, we have relied on the theoretical work by Tabakis (2010, 2015). Three main testable predictions regarding PTAs and AD measures emerge from these papers: (i) the number of $\mathrm{AD}$ measures of members against non-members of an FTA agreement should decrease both during its negotiation and after its implementation; (ii) the number of $\mathrm{AD}$ measures of members against non-members of a $\mathrm{CU}$ agreement should decrease during its negotiation; and (iii) the number of $\mathrm{AD}$ measures of members against non-members of a CU agreement should increase following its implementation for "high" import volumes from non-member countries, whereas the reverse is true for "low" volumes of imports.

\footnotetext{
${ }^{29}$ Clustering the standard errors at the importer level only would instead lead to few clusters (15 in total), contradicting the assumption behind theory that the number of clusters should go to infinity (usually interpreted as a minimum of 50 in state-year panels; see Cameron and Miller, 2015).
} 
To empirically test these predictions, we have first constructed a dataset containing extensive information regarding the negotiation, signature, ratification, and implementation of a large number of PTAs. The novel dataset that we have created allows us to distinguish between the negotiation and the implementation phases of PTAs. Using then AD data over the period 1980-2015 and different econometric strategies, we have provided clear evidence in support of the aforementioned predictions. PTAs have, in general, a dampening effect on their member countries' AD activity against the rest of the world (i.e., they produce a building-block effect), except when members of an implemented CU agreement face large import surges from non-member countries. In such case, the building-block effect may disappear albeit without the (clear) emergence instead of a stumbling-block effect. These results provide a new piece of evidence on the (mostly) positive effects of PTAs on multilateral trade cooperation, at least as far as AD protection is concerned, and the differential effect we uncover between FTA and $\mathrm{CU}$ agreements on the multilateral trading system is very much in line with the results of Estevadeordal et al. (2008). Finally, the findings of our paper are particularly important in light of the fact that non-tariff barriers have nowadays gained prominence relative to MFN tariffs, which have dramatically decreased in recent decades because of WTO commitments. And among non-tariff barriers, AD is the most flexible and widely employed trade policy instrument. $^{30}$

In conclusion, this paper offers yet further evidence that strategic interactions - either across countries or between a given country's policies - play a pivotal role in trade policy formulation (see, e.g., Bown and Crowley, 2007; Tabakis and Zanardi, 2017). In particular, we have demonstrated that a country's decision to engage in regionalism has important ramifications for its AD activity vis-à-vis the rest of the world. What is more significant, our analysis highlights the importance of taking into consideration other policy instruments besides MFN tariffs in order to get a more comprehensive picture regarding whether PTAs are building blocks or stumbling blocks towards multilateral trade cooperation.

\footnotetext{
${ }^{30}$ Notice that our results are not contradicted by the fact that the worldwide caseload of AD measures has been growing over the last decades. This increase is the result of, among other things, an increasing level of international trade. However, our results indicate that we would have seen even more AD measures worldwide had it not been for the PTAs that have been negotiated and implemented.
} 


\section{References}

[1] Ahn, Dukgeun, and Wonkyu Shin (2011). "Analysis of Anti-Dumping Use in Free Trade Agreements." Journal of World Trade, 45, 431-456.

[2] Allison, Paul D., and Richard P. Waterman (2002). "Fixed-Effects Negative Binomial Regression Models." Sociological Methodology, 32, 247-265.

[3] Bagwell, Kyle, and Robert W. Staiger (1990). "A Theory of Managed Trade." American Economic Review, 80, 779-795.

[4] Bagwell, Kyle, and Robert W. Staiger (1997a). "Multilateral Tariff Cooperation during the Formation of Free Trade Areas." International Economic Review, 38, 291-319.

[5] Bagwell, Kyle, and Robert W. Staiger (1997b). "Multilateral Tariff Cooperation during the Formation of Customs Unions." Journal of International Economics, 42, 91-123.

[6] Bagwell, Kyle, and Robert W. Staiger (1999). "Regionalism and Multilateral Tariff Cooperation," in John Piggott and Alan Woodland (eds.), International Trade Policy and the Pacific Rim. Palgrave Macmillan.

[7] Bagwell, Kyle, and Robert W. Staiger (2002). The Economics of the World Trading System. MIT Press.

[8] Bagwell, Kyle, and Robert W. Staiger (2011). "What Do Trade Negotiators Negotiate About? Empirical Evidence from the World Trade Organization." American Economic Review, 101, 1238-1273.

[9] Bhagwati, Jagdish N. (1991). The World Trading System at Risk. Princeton University Press.

[10] Blonigen, Bruce A., and Thomas J. Prusa (2003). "Antidumping," in E. Kwan Choi and James Harrigan (eds.), Handbook of International Trade. Blackwell Publishing.

[11] Bond, Eric W., Raymond G. Riezman, and Constantinos Syropoulos (2004). "A Strategic and Welfare Theoretic Analysis of Free Trade Areas." Journal of International Economics, $64,1-27$. 
[12] Bown, Chad P. (2015). Global Antidumping Database. The World Bank (version Q42015).

[13] Bown, Chad P., and Meredith A. Crowley (2007). "Trade Deflection and Trade Depression." Journal of International Economics, 72, 176-201.

[14] Bown, Chad P., and Meredith A. Crowley (2013). "Self-Enforcing Trade Agreements: Evidence from Time-Varying Trade Policy." American Economic Review, 103, 1071-1090.

[15] Bown, Chad P., and Meredith A. Crowley (2016). "The Empirical Landscape of Trade Policy," in Kyle Bagwell and Robert W. Staiger (eds.), Handbook of Commercial Policy, Vol. 1A. Elsevier, North-Holland.

[16] Broda, Christian, Nuno Limão, and David E. Weinstein (2008). "Optimal Tariffs and Market Power: The Evidence." American Economic Review, 98, 2032-2065.

[17] Cameron, Colin A., and Douglas L. Miller (2015). "A Practitioner's Guide to ClusterRobust Inference." Journal of Human Resources, 50, 317-372.

[18] de Sousa, José (2012). "The Currency Union Effect on Trade Is Decreasing over Time." Economics Letters, 117, 917-920.

[19] Dür, Andreas, Leonardo Baccini, and Manfred Elsig (2014). "The Design of International Trade Agreements: Introducing a New Database." Review of International Organizations, 9, 353-375.

[20] Estevadeordal, Antoni, Caroline Freund, and Emanuel Ornelas (2008). "Does Regionalism Affect Trade Liberalization toward Nonmembers?" Quarterly Journal of Economics, 123, $1531-1575$.

[21] Freund, Caroline, and Emanuel Ornelas (2010). "Regional Trade Agreements." Annual Review of Economics, 2, 139-166.

[22] Karacaovali, Baybars, and Nuno Limão (2008). "The Clash of Liberalizations: Preferential vs. Multilateral Trade Liberalization in the European Union." Journal of International Economics, 74, 299-327. 
[23] Knetter, Michael M., and Thomas J. Prusa (2003). "Macroeconomic Factors and Antidumping Filings: Evidence from Four Countries." Journal of International Economics, $61,1-17$.

[24] Krugman, Paul R. (1991). "Is Bilateralism Bad?" in Elhanan Helpman and Assaf Razin (eds.), International Trade and Trade Policy. MIT Press.

[25] Limão, Nuno (2006). "Preferential Trade Agreements as Stumbling Blocks for Multilateral Trade Liberalization: Evidence for the United States." American Economic Review, 96, 896-914.

[26] Limão, Nuno (2016). "Preferential Trade Agreements," in Kyle Bagwell and Robert W. Staiger (eds.), Handbook of Commercial Policy, Vol. 1B. Elsevier, North-Holland.

[27] Moore, Michael O., and Maurizio Zanardi (2009). "Does Antidumping Use Contribute to Trade Liberalization in Developing Countries?" Canadian Journal of Economics, 42, 469-495.

[28] Ornelas, Emanuel (2005). "Endogenous Free Trade Agreements and the Multilateral Trading System." Journal of International Economics, 67, 471-497.

[29] Prusa, Thomas J., and Robert Teh (2010). "Protection Reduction and Diversion: PTAs and the Incidence of Antidumping Disputes." NBER Working Paper 16276.

[30] Silberberger, Magdalene, and Frederik Stender (forthcoming). "False Friends? Empirical Evidence on Trade Policy Substitution in Regional Trade Agreements." The World Economy.

[31] Tabakis, Chrysostomos (2010). "Customs Unions and Special Protection." The B.E. Journal of Economic Analysis \&3 Policy, 10 (Contributions), 1-40.

[32] Tabakis, Chrysostomos (2015). "Free-Trade Areas and Special Protection." The Journal of International Trade $\& 3$ Economic Development, 24, 1054-1076.

[33] Tabakis, Chrysostomos, and Maurizio Zanardi (2017). "Antidumping Echoing." Economic Inquiry, 55, 655-681. 
Figure 1: Customs Unions

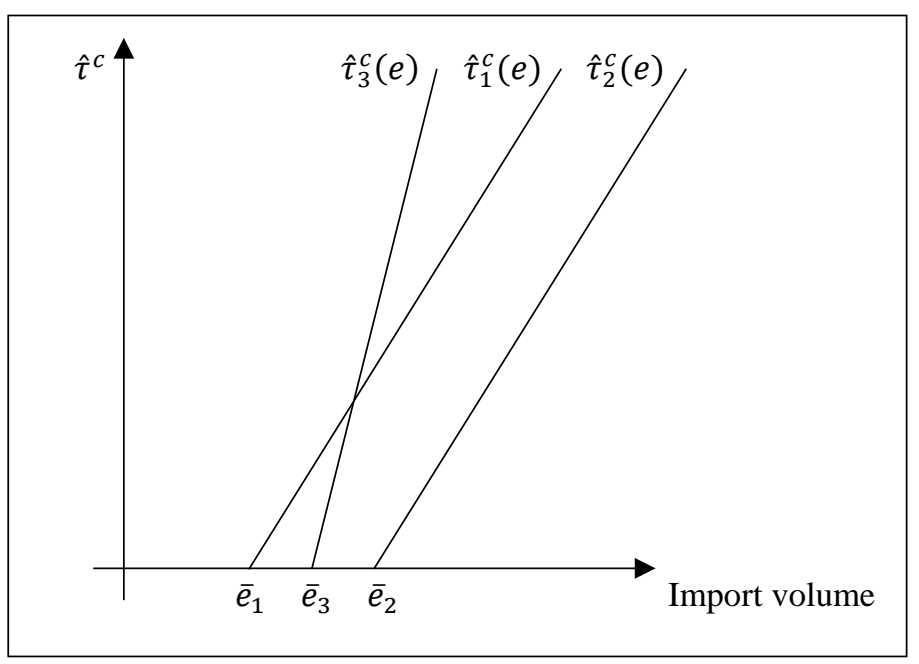

Figure 2: Free-Trade Areas

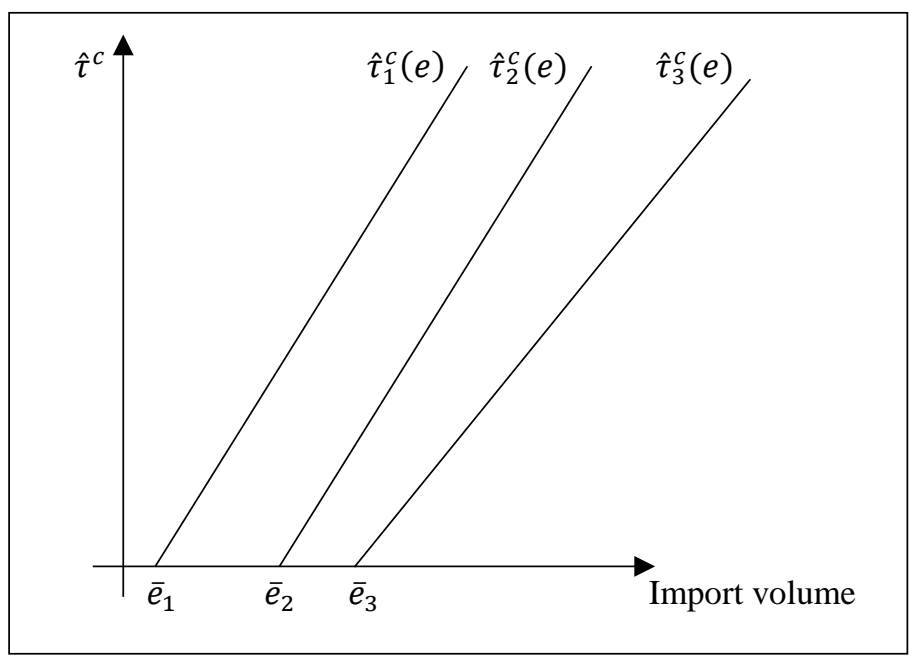


Table 1: Summary statistics on worldwide AD use

\begin{tabular}{|c|c|c|c|c|c|c|c|}
\hline \multicolumn{2}{|l|}{ Initiations } & \multicolumn{2}{|c|}{ Initiations per year } & \multicolumn{2}{|l|}{ Measures } & \multicolumn{2}{|c|}{ Measures per year } \\
\hline USA & 1,343 & USA & 37.31 & European Union & 643 & India & 23.25 \\
\hline European Union & 1,056 & India & 31.83 & USA & 614 & European Union & 17.86 \\
\hline India & 764 & European Union & 29.33 & India & 558 & USA & 17.06 \\
\hline Canada & 577 & Australia & 21.30 & Canada & 350 & Canada & 9.72 \\
\hline Australia & 575 & Brazil & 16.07 & Argentina & 252 & China & 9.58 \\
\hline Brazil & 450 & Canada & 16.03 & Brazil & 247 & Argentina & 9.33 \\
\hline Argentina & 380 & Argentina & 14.07 & Turkey & 214 & Brazil & 8.82 \\
\hline South Africa & 306 & South Africa & 13.30 & Australia & 204 & Turkey & 7.93 \\
\hline Mexico & 285 & China & 12.21 & China & 182 & Australia & 7.56 \\
\hline Turkey & 285 & Turkey & 10.56 & South Africa & 171 & South Africa & 7.43 \\
\hline China & 232 & Mexico & 9.83 & Mexico & 158 & Mexico & 5.45 \\
\hline South Korea & 166 & Pakistan & 6.71 & South Korea & 93 & Vietnam & 4.00 \\
\hline Taiwan & 141 & Indonesia & 6.35 & Peru & 63 & Pakistan & 3.64 \\
\hline Indonesia & 127 & South Korea & 5.53 & Indonesia & 61 & Lithuania & 3.50 \\
\hline Peru & 115 & Peru & 4.79 & New Zealand & 56 & South Korea & 3.10 \\
\hline New Zealand & 109 & Taiwan & 4.55 & Egypt & 53 & Indonesia & 3.05 \\
\hline Colombia & 101 & Egypt & 4.47 & Pakistan & 51 & Egypt & 2.79 \\
\hline Pakistan & 94 & Colombia & 4.04 & Thailand & 47 & Russia & 2.73 \\
\hline Egypt & 85 & Malaysia & 4.00 & Colombia & 44 & Peru & 2.63 \\
\hline Malaysia & 84 & Sweden & 4.00 & Malaysia & 43 & Thailand & 2.35 \\
\hline Israel & 68 & Vietnam & 4.00 & Russia & 41 & Malaysia & 2.05 \\
\hline Thailand & 68 & Russia & 3.53 & Taiwan & 33 & Singapore & 2.00 \\
\hline Russia & 53 & Latvia & 3.50 & Ukraine & 28 & Ukraine & 1.87 \\
\hline Ukraine & 37 & Lithuania & 3.50 & Israel & 25 & Colombia & 1.76 \\
\hline Philippines & 29 & New Zealand & 3.41 & Venezuela & 16 & New Zealand & 1.75 \\
\hline Chile & 28 & Thailand & 3.40 & Philippines & 13 & Venezuela & 1.60 \\
\hline Venezuela & 27 & Honduras & 3.00 & Chile & 9 & Kazakhstan & 1.33 \\
\hline Japan & 14 & Israel & 2.72 & Finland & 9 & Poland & 1.29 \\
\hline Finland & 13 & Venezuela & 2.70 & Japan & 9 & Taiwan & 1.06 \\
\hline Poland & 12 & Ukraine & 2.47 & Poland & 9 & Israel & 1.00 \\
\hline Trinidad and & 12 & Kazakhstan & 2.33 & Lithuania & 7 & Finland & 0.75 \\
\hline Austria & 11 & Singapore & 2.00 & Morocco & 7 & Morocco & 0.70 \\
\hline Costa Rica & 11 & Poland & 1.71 & Trinidad and & 7 & Philippines & 0.62 \\
\hline Morocco & 9 & Czech Republic & 1.50 & Jamaica & 4 & Czech Republic & 0.50 \\
\hline Sweden & 8 & Nicaragua & 1.50 & Kazakhstan & 4 & Dominican Republic & 0.50 \\
\hline Uruguay & 8 & Philippines & 1.38 & Vietnam & 4 & Latvia & 0.50 \\
\hline Kazakhstan & 7 & Chile & 1.33 & Costa Rica & 3 & Nicaragua & 0.50 \\
\hline Latvia & 7 & Finland & 1.08 & Austria & 2 & Chile & 0.43 \\
\hline Lithuania & 7 & Bulgaria & 1.00 & Dominican Republic & 2 & Trinidad and & 0.37 \\
\hline Jamaica & 6 & GCC & 1.00 & Ecuador & 2 & Jamaica & 0.36 \\
\hline Panama & 6 & Jordan & 1.00 & Paraguay & 2 & Japan & 0.36 \\
\hline Ecuador & 5 & Norway & 1.00 & Singapore & 2 & Paraguay & 0.33 \\
\hline Vietnam & 4 & Slovenia & 1.00 & Uruguay & 2 & Austria & 0.15 \\
\hline Czech Republic & 3 & Morocco & 0.90 & Czech Republic & 1 & Ecuador & 0.15 \\
\hline Dominican Republic & 3 & Austria & 0.85 & Guatemala & 1 & Costa Rica & 0.15 \\
\hline Honduras & 3 & Dominican Republic & 0.75 & Latvia & 1 & Uruguay & 0.11 \\
\hline Nicaragua & 3 & Trinidad and & 0.63 & Nicaragua & 1 & Guatemala & 0.05 \\
\hline Guatemala & 2 & Japan & 0.56 & Bulgaria & 0 & Bulgaria & 0.00 \\
\hline Paraguay & 2 & Costa Rica & 0.55 & GCC & 0 & GCC & 0.00 \\
\hline Singapore & 2 & Jamaica & 0.55 & Honduras & 0 & Honduras & 0.00 \\
\hline Bulgaria & 1 & Panama & 0.50 & Jordan & 0 & Jordan & 0.00 \\
\hline GCC & 1 & Uruguay & 0.42 & Norway & 0 & Norway & 0.00 \\
\hline Jordan & 1 & Ecuador & 0.38 & Panama & 0 & Panama & 0.00 \\
\hline Norway & 1 & Paraguay & 0.33 & Slovenia & 0 & Slovenia & 0.00 \\
\hline Slovenia & 1 & Guatemala & 0.11 & Sweden & 0 & Sweden & 0.00 \\
\hline
\end{tabular}

Notes: Countries in bold and italics are included in the econometric analysis. GCC stands for the six Middle Eastern countries of the Gulf Cooperation Council. 
Table 2: Summary statistics

\begin{tabular}{|c|c|c|c|c|c|}
\hline Variable & Obs. & Average & St. Dev. & Min & Max \\
\hline $\mathrm{AD}_{\mathrm{i}, \mathrm{j}, \mathrm{t}}$ & 18,243 & 0.151 & 0.672 & 0 & 14 \\
\hline PTAs negotiation ${ }_{\mathrm{i}, \mathrm{k}, \mathrm{t}}$ & 18,243 & 0.367 & 0.679 & 0 & 5 \\
\hline PTAs implementedi,k,t & 18,243 & 0.765 & 0.938 & 0 & 5 \\
\hline $\ln \left(1+\right.$ PTAs negotiation $\left.n_{i, k, t}\right)$ & 18,243 & 0.228 & 0.377 & 0 & 1.792 \\
\hline $\ln \left(1+\right.$ PTAs implemented $\left.\mathrm{d}_{\mathrm{i}, \mathrm{k}, \mathrm{t}}\right)$ & 18,243 & 0.449 & 0.474 & 0 & 1.792 \\
\hline FTAs negotiation ${ }_{i, k, t}$ & 18,243 & 0.301 & 0.663 & 0 & 5 \\
\hline CUs negotiationi,k,t & 18,243 & 0.065 & 0.247 & 0 & 1 \\
\hline $\ln \left(1+\right.$ FTAs negotiation $\left.{ }_{i, k, t}\right)$ & 18,243 & 0.183 & 0.360 & 0 & 1.792 \\
\hline $\ln \left(1+\right.$ CUs negotiation $\left.n_{i, k, t}\right)$ & 18,243 & 0.045 & 0.171 & 0 & 0.693 \\
\hline FTAs implemented $\mathrm{d}_{\mathrm{i}, \mathrm{k}, \mathrm{t}}$ & 18,243 & 0.558 & 0.956 & 0 & 5 \\
\hline CUs implemented $\mathrm{d}_{\mathrm{i}, \mathrm{k}, \mathrm{t}}$ & 18,243 & 0.207 & 0.444 & 0 & 2 \\
\hline $\ln \left(1+\right.$ FTAs implemented $\left.\mathrm{d}_{\mathrm{i}, \mathrm{k}, \mathrm{t}}\right)$ & 18,243 & 0.310 & 0.476 & 0 & 1.792 \\
\hline $\ln \left(1+\right.$ CUs implemented $\left.\mathrm{i}_{\mathrm{i}, \mathrm{t}, \mathrm{t}}\right)$ & 18,243 & 0.139 & 0.290 & 0 & 1.098 \\
\hline Import growth $\mathrm{h}_{\mathrm{i}, \mathrm{j}, \mathrm{t} t-1}$ & 18,243 & 0.258 & 0.909 & -1 & 6.063 \\
\hline $\ln (\text { Imports })_{\mathrm{i}, \mathrm{j}, \mathrm{t}-1}$ & 18,243 & 19.401 & 3.041 & 0 & 26.901 \\
\hline $\ln (\text { Real exchange rate })_{\mathrm{i}, \mathrm{j}, \mathrm{t}-1}$ & 18,243 & 0.500 & 3.674 & -11.073 & 10.795 \\
\hline Importer GDP growth $\mathrm{i}_{\mathrm{i}, \mathrm{t} / \mathrm{t}-3}$ & 18,243 & 0.120 & 0.091 & -0.155 & 0.433 \\
\hline Exporter GDP growth $_{\mathrm{j}, \mathrm{t} / \mathrm{t}-3}$ & 18,243 & 0.113 & 0.095 & -0.437 & 0.532 \\
\hline
\end{tabular}

Note: Import growth has been winsorized at the $95^{\text {th }}$ percentile. 
Table 3: Step 1

$$
\text { (1) }
$$

(3)

(4)

(5)

(6)

(7)

(8)

\begin{tabular}{|c|c|c|c|c|c|c|c|c|}
\hline \multirow[b]{2}{*}{ PTAs negotiation $n_{i, k, t}$} & & & & & \multicolumn{4}{|c|}{$\ln (1+$ PTAs negotiation) and $\ln (1+\mathrm{PTAs}$ implemented) } \\
\hline & $\begin{array}{c}-0.240^{* * *} \\
(0.070)\end{array}$ & $\begin{array}{c}-0.291^{* * *} \\
(0.071)\end{array}$ & $\begin{array}{c}-0.208^{* * *} \\
(0.074)\end{array}$ & $\begin{array}{c}-0.292^{* * *} \\
(0.072)\end{array}$ & $\begin{array}{c}-0.310^{* * *} \\
(0.108)\end{array}$ & $\begin{array}{c}-0.380^{* * *} \\
(0.107)\end{array}$ & $\begin{array}{c}-0.250^{* *} \\
(0.116)\end{array}$ & $\begin{array}{c}-0.381^{* * *} \\
(0.109)\end{array}$ \\
\hline PTAs implemented $\mathrm{d}_{\mathrm{i}, \mathrm{k}, \mathrm{t}}$ & $\begin{array}{c}-0.425^{* * *} \\
(0.106)\end{array}$ & $\begin{array}{c}-0.416^{* * *} \\
(0.116)\end{array}$ & $\begin{array}{c}-0.413^{* * *} \\
(0.108)\end{array}$ & $\begin{array}{c}-0.410^{* * * *} \\
(0.113)\end{array}$ & $\begin{array}{c}-0.619^{* * *} \\
(0.159)\end{array}$ & $\begin{array}{c}-0.577^{* * *} \\
(0.171)\end{array}$ & $\begin{array}{c}-0.569^{* * *} \\
(0.164)\end{array}$ & $\begin{array}{c}-0.578^{* * *} \\
(0.173)\end{array}$ \\
\hline Import growth $\mathrm{i}_{\mathrm{i}, \mathrm{j}, \mathrm{t} / \mathrm{t}-1}$ & & $\begin{array}{c}0.083 \\
(0.066)\end{array}$ & & $\begin{array}{c}0.101 \\
(0.071)\end{array}$ & & $\begin{array}{c}0.084 \\
(0.065)\end{array}$ & & $\begin{array}{c}0.105 \\
(0.071)\end{array}$ \\
\hline $\ln (\text { Imports })_{\mathrm{i}, \mathrm{j}, \mathrm{t}-1}$ & & $\begin{array}{c}0.491^{* * *} \\
(0.045)\end{array}$ & & $\begin{array}{c}0.590^{* * *} \\
(0.069)\end{array}$ & & $\begin{array}{c}0.499^{* * *} \\
(0.045)\end{array}$ & & $\begin{array}{c}0.606^{* * *} \\
(0.069)\end{array}$ \\
\hline $\ln (\text { Real exchange rate })_{\mathrm{i}, \mathrm{j}, \mathrm{t}-1}$ & & $\begin{array}{c}0.757^{* * *} \\
(0.127)\end{array}$ & & $\begin{array}{c}0.755^{* * *} \\
(0.136)\end{array}$ & & $\begin{array}{c}0.743^{* * *} \\
(0.127)\end{array}$ & & $\begin{array}{c}0.739^{* * *} \\
(0.136)\end{array}$ \\
\hline Importer GDP growthi,t/t-3 & & $\begin{array}{l}-0.186 \\
(0.480)\end{array}$ & & $\begin{array}{l}-0.595 \\
(0.496)\end{array}$ & & $\begin{array}{l}-0.225 \\
(0.475)\end{array}$ & & $\begin{array}{l}-0.648 \\
(0.492)\end{array}$ \\
\hline Exporter GDP growth $_{\mathrm{j}, t / t-3}$ & & $\begin{array}{c}-0.032 \\
(0.375)\end{array}$ & & $\begin{array}{l}-0.073 \\
(0.385)\end{array}$ & & $\begin{array}{l}-0.037 \\
(0.375)\end{array}$ & & $\begin{array}{c}-0.086 \\
(0.387)\end{array}$ \\
\hline Year FE & Yes & Yes & Yes & Yes & Yes & Yes & Yes & Yes \\
\hline Importer FE & Yes & Yes & No & No & Yes & Yes & No & No \\
\hline Exporter FE & Yes & Yes & No & No & Yes & Yes & No & No \\
\hline Dyad FE & No & No & Yes & Yes & No & No & Yes & Yes \\
\hline Observations & 28,144 & 18,243 & 11,653 & 9,142 & 28,144 & 18,243 & 11,653 & 9,142 \\
\hline Pseudo $\mathrm{R}^{2}$ & 0.28 & 0.29 & 0.21 & 0.23 & 0.28 & 0.29 & 0.21 & 0.23 \\
\hline
\end{tabular}

Notes: The dependent variable is the count of AD measures introduced by country $i$ against country $j$ in year $t$. PTAs are included in the regressors if they affect at least $10 \%$ of the import volume of the importing country. The table reports the estimated coefficients of negative binomial regressions with standard errors clustered at country-pair level; $* * *, * *, *$ denote significance at the $1 \%, 5 \%$, and $10 \%$ level, respectively. 
Table 4: Step 2

\begin{tabular}{|c|c|c|c|c|}
\hline \multirow[b]{2}{*}{ FTAs negotiation $_{\mathrm{i}, \mathrm{k}, \mathrm{t}}$} & \multirow{2}{*}{$\begin{array}{c}(1) \\
-0.145^{* *} \\
(0.068)\end{array}$} & \multirow{2}{*}{$\begin{array}{c}(2) \\
-0.155^{* *} \\
(0.073)\end{array}$} & \multicolumn{2}{|c|}{$\begin{array}{l}(3) \\
\ln (1+\text { negotiation }) \text { and } \\
\ln (1+\text { implemented })\end{array}$} \\
\hline & & & $\begin{array}{l}-0.162 \\
(0.104)\end{array}$ & $\begin{array}{l}-0.185 \\
(0.112)\end{array}$ \\
\hline CUs negotiation ${ }_{i, k, t}$ & $\begin{array}{c}-0.678^{* * *} \\
(0.170)\end{array}$ & $\begin{array}{c}-0.674^{* * *} \\
(0.177)\end{array}$ & $\begin{array}{c}-0.897^{* * *} \\
(0.248)\end{array}$ & $\begin{array}{c}-0.894^{* * *} \\
(0.258)\end{array}$ \\
\hline FTAs implementedi,k,t & $\begin{array}{c}-0.511^{* * *} \\
(0.134)\end{array}$ & $\begin{array}{c}-0.511^{* * *} \\
(0.132)\end{array}$ & $\begin{array}{c}-0.827^{* * *} \\
(0.201)\end{array}$ & $\begin{array}{c}-0.844^{* * *} \\
(0.205)\end{array}$ \\
\hline FTAs implementedi,k,t $x$ Import growth I $_{\mathrm{i}, \mathrm{j}, \mathrm{t} t-1}$ & $\begin{array}{c}0.036 \\
(0.174)\end{array}$ & $\begin{array}{c}0.100 \\
(0.122)\end{array}$ & $\begin{array}{c}0.032 \\
(0.279)\end{array}$ & $\begin{array}{c}0.147 \\
(0.210)\end{array}$ \\
\hline CUs implementedi,k,t & $\begin{array}{l}-0.280^{*} \\
(0.152)\end{array}$ & $\begin{array}{c}-0.340^{* *} \\
(0.150)\end{array}$ & $\begin{array}{l}-0.215 \\
(0.254)\end{array}$ & $\begin{array}{l}-0.333 \\
(0.257)\end{array}$ \\
\hline CUs implemented ${ }_{i, k, t} \times$ Import growth $_{\mathrm{i}, \mathrm{j}, \mathrm{t} t \mathrm{-1}}$ & $\begin{array}{c}0.427^{* * *} \\
(0.109)\end{array}$ & $\begin{array}{c}0.429^{* * *} \\
(0.113)\end{array}$ & $\begin{array}{c}0.622^{* * *} \\
(0.163)\end{array}$ & $\begin{array}{l}0.637^{* * *} \\
(0.170)\end{array}$ \\
\hline Import growth $\mathrm{i}_{\mathrm{j}, \mathrm{t}, \mathrm{tt}-\mathrm{1}}$ & $\begin{array}{l}-0.012 \\
(0.082)\end{array}$ & $\begin{array}{c}0.001 \\
(0.080)\end{array}$ & $\begin{array}{l}-0.013 \\
(0.084)\end{array}$ & $\begin{array}{l}-0.000 \\
(0.082)\end{array}$ \\
\hline $\ln (\text { Imports })_{\mathrm{i}, \mathrm{j}, \mathrm{t}-1}$ & $\begin{array}{c}0.478^{* * * *} \\
(0.043)\end{array}$ & $\begin{array}{l}0.558^{* * * *} \\
(0.067)\end{array}$ & $\begin{array}{l}0.482^{* * *} \\
(0.043)\end{array}$ & $\begin{array}{l}0.567^{* * *} \\
(0.067)\end{array}$ \\
\hline $\ln (\text { Real exchange rate })_{\mathrm{i}, \mathrm{j}, \mathrm{t}-1}$ & $\begin{array}{c}0.775^{* * *} \\
(0.129)\end{array}$ & $\begin{array}{c}0.771^{* * *} \\
(0.140)\end{array}$ & $\begin{array}{c}0.759^{* * *} \\
(0.130)\end{array}$ & $\begin{array}{l}0.749^{* * *} \\
(0.140)\end{array}$ \\
\hline Importer GDP growthi,t/t-3 & $\begin{array}{l}-0.002 \\
(0.508)\end{array}$ & $\begin{array}{l}-0.450 \\
(0.534)\end{array}$ & $\begin{array}{c}0.058 \\
(0.507)\end{array}$ & $\begin{array}{l}-0.402 \\
(0.535)\end{array}$ \\
\hline Exporter GDP growth $_{\mathrm{j}, \mathrm{t} / \mathrm{t}-3}$ & $\begin{array}{l}-0.166 \\
(0.385)\end{array}$ & $\begin{array}{l}-0.200 \\
(0.391)\end{array}$ & $\begin{array}{l}-0.185 \\
(0.389)\end{array}$ & $\begin{array}{l}-0.231 \\
(0.396)\end{array}$ \\
\hline Year FE & Yes & Yes & Yes & Yes \\
\hline Importer FE & Yes & No & Yes & No \\
\hline Exporter FE & Yes & No & Yes & No \\
\hline Dyad FE & No & Yes & No & Yes \\
\hline Observations & $\begin{array}{c}18,243 \\
029\end{array}$ & 9,142 & 18,243 & 9,142 \\
\hline
\end{tabular}

Notes: The dependent variable is the count of AD measures introduced by country $i$ against country $j$ in year $t$. PTAs are included in the regressors if they affect at least $10 \%$ of the import volume of the importing country. The table reports the estimated coefficients of negative binomial regressions with standard errors clustered at country-pair level; $* * *, * *, *$ denote significance at the $1 \%, 5 \%$, and $10 \%$ level, respectively. 
Table 5: Predicted counts of Step 1

\begin{tabular}{lcc}
\hline & $(1)$ & $(2)$ \\
\hline C(PTAs negotiation=0, PTAs implemented=0) & $0.470^{* * *}$ & $0.441^{* * *}$ \\
& $(0.055)$ & $(0.047)$ \\
C(PTAs negotiation=1, PTAs implemented=0) & $0.351^{* * *}$ & $0.338^{* * *}$ \\
& $(0.033)$ & $(0.029)$ \\
C(PTAs negotiation=0, PTAs implemented=1) & $0.312^{* * *}$ & $0.295^{* * *}$ \\
& $(0.007)$ & $(0.008)$ \\
C(PTAs negotiation=1, PTAs implemented=1) & $0.233^{* * *}$ & $0.226^{* * *}$ \\
& $(0.013)$ & $(0.016)$ \\
\hline Observations & 9,142 & 9,142 \\
\hline
\end{tabular}

Notes: The table reports average predicted counts for columns (4) and (8) of Table 3 conditioning on the variables in the $\mathrm{C}(\bullet)$ function (in Table 5) taking on the specified values while the other variables are taking their actual values. $* * *, * *, *$ denote significance at the $1 \%, 5 \%$, and $10 \%$ level, respectively.

Table 6: Predicted counts of Step 2

\begin{tabular}{|c|c|c|}
\hline & (1) & (2) \\
\hline \multicolumn{3}{|l|}{ Role of FTAs: } \\
\hline $\mathrm{C}$ (FTAs negotiation $=0$, FTAs implemented $=0$ ) & $\begin{array}{c}0.424^{* * *} \\
(0.044)\end{array}$ & $\begin{array}{c}0.415^{* * *} \\
(0.038)\end{array}$ \\
\hline C(FTAs negotiation $=1$, FTAs implemented $=0$ ) & $\begin{array}{l}0.363^{* * *} \\
(0.033)\end{array}$ & $\begin{array}{l}0.365^{* * *} \\
(0.030)\end{array}$ \\
\hline $\mathrm{C}\left(\right.$ FTAs negotiation $=0$, FTAs implemented $=1$, imp. growth $\left.=25^{\text {th }} \mathrm{pct}\right)$ & $\begin{array}{l}0.249^{* * *} \\
(0.010)\end{array}$ & $\begin{array}{c}0.226^{* * *} \\
(0.013)\end{array}$ \\
\hline $\mathrm{C}\left(\right.$ FTAs negotiation $=0$, FTAs implemented $=1$, imp. growth $\left.=75^{\text {th }} \mathrm{pct}\right)$ & $\begin{array}{l}0.264^{* * *} \\
(0.012)\end{array}$ & $\begin{array}{l}0.240^{* * *} \\
(0.015)\end{array}$ \\
\hline $\mathrm{C}\left(\right.$ FTAs negotiation $=1$, FTAs implemented $=1$, imp. growth $\left.=25^{\text {th }} \mathrm{pct}\right)$ & $\begin{array}{l}0.214^{* * *} \\
(0.017)\end{array}$ & $\begin{array}{c}0.199^{* * *} \\
(0.020)\end{array}$ \\
\hline$C\left(\right.$ FTAs negotiation $=1$, FTAs implemented $=1$, imp. growth $\left.=75^{\text {th }} p c t\right)$ & $\begin{array}{c}0.226^{* * * *} \\
(0.018)\end{array}$ & $\begin{array}{c}0.211^{* * *} \\
(0.021)\end{array}$ \\
\hline Role of CUs: & & \\
\hline $\mathrm{C}(\mathrm{CUs}$ negotiation $=0$, CUs implemented $=0$ ) & $\begin{array}{l}0.359^{* * *} \\
(0.025)\end{array}$ & $\begin{array}{l}0.342^{* * *} \\
(0.024)\end{array}$ \\
\hline $\mathrm{C}(\mathrm{CUs}$ negotiation $=1$, CUs implemented $=0$ ) & $\begin{array}{c}0.183^{* * *} \\
(0.026)\end{array}$ & $\begin{array}{l}0.184^{* * *} \\
(0.026)\end{array}$ \\
\hline$C\left(\right.$ CUs negotiation $=0$, CUs implemented $=1$, imp. growth $\left.=25^{\text {th }} \mathrm{pct}\right)$ & $\begin{array}{l}0.249^{* * *} \\
(0.021)\end{array}$ & $\begin{array}{l}0.264^{* * *} \\
(0.030)\end{array}$ \\
\hline$C\left(\right.$ CUs negotiation $=0$, CUs implemented $=1$, imp. growth $\left.=75^{\text {th }} \mathrm{pct}\right)$ & $\begin{array}{l}0.287^{* * *} \\
(0.024)\end{array}$ & $\begin{array}{l}0.305^{* * *} \\
(0.034)\end{array}$ \\
\hline$C\left(\right.$ CUs negotiation $=1$, CUs implemented $=1$, imp. growth $\left.=25^{\text {th }} \mathrm{pct}\right)$ & $\begin{array}{l}0.127^{* * *} \\
(0.028)\end{array}$ & $\begin{array}{l}0.142^{* * *} \\
(0.035)\end{array}$ \\
\hline$C\left(\right.$ CUs negotiation $=1$, CUs implemented $=1$, imp. growth $\left.=75^{\text {th }} p c t\right)$ & $\begin{array}{l}0.146^{* * *} \\
(0.032)\end{array}$ & $\begin{array}{c}0.164^{* * *} \\
(0.041)\end{array}$ \\
\hline Observations & 9,142 & 9,142 \\
\hline
\end{tabular}

Notes: The table reports average predicted counts for columns (2) and (4) of Table 4 conditioning on the variables in the $\mathrm{C}(\bullet)$ function (in Table 6 ) taking on the specified values while the other variables are taking their actual values. ${ }^{* * *}$, $* *$, * denote significance at the $1 \%, 5 \%$, and $10 \%$ level, respectively. 
Table 7: Robustness: threshold for included PTAs

\begin{tabular}{|c|c|c|c|c|}
\hline & (1) & $\begin{array}{c}(2) \\
\ln (1+X)\end{array}$ & (3) & $\begin{array}{c}(4) \\
\ln (1+X) \\
\end{array}$ \\
\hline PTAs negotiation $_{i, k, t}$ & $\begin{array}{c}-0.161^{* * *} \\
(0.062)\end{array}$ & $\begin{array}{c}-0.233^{* *} \\
(0.102)\end{array}$ & & \\
\hline PTAs implemented ${ }_{i, k, t}$ & $\begin{array}{c}-0.400^{* * *} \\
(0.107)\end{array}$ & $\begin{array}{c}-0.622^{* * *} \\
(0.164)\end{array}$ & & \\
\hline FTAs negotiation $_{\mathrm{i}, \mathrm{k}, \mathrm{t}}$ & & & $\begin{array}{c}-0.010 \\
(0.061)\end{array}$ & $\begin{array}{c}0.067 \\
(0.105)\end{array}$ \\
\hline CUs negotiation $n_{\mathrm{i}, \mathrm{k}, \mathrm{t}}$ & & & $\begin{array}{c}-0.626^{* * *} \\
(0.160)\end{array}$ & $\begin{array}{c}-0.834^{* * *} \\
(0.274)\end{array}$ \\
\hline FTAs implemented $\mathrm{i}_{\mathrm{i}, \mathrm{k}, \mathrm{t}}$ & & & $\begin{array}{c}-0.474^{* * *} \\
(0.118)\end{array}$ & $\begin{array}{c}-0.807^{* * *} \\
(0.171)\end{array}$ \\
\hline FTAs implemented ${ }_{i, k, t} x$ Import growth ${ }_{i, j, t / t-1}$ & & & $\begin{array}{c}0.150 \\
(0.095)\end{array}$ & $\begin{array}{c}0.290 \\
(0.207)\end{array}$ \\
\hline CUs implemented $\mathrm{i}_{\mathrm{i}, \mathrm{k}, \mathrm{t}}$ & & & $\begin{array}{c}-0.391^{* * *} \\
(0.151)\end{array}$ & $\begin{array}{l}-0.516 \\
(0.363)\end{array}$ \\
\hline CUs implemented $\mathrm{i}_{\mathrm{i}, \mathrm{k}, \mathrm{x}} \mathrm{X}$ Import growth $\mathrm{i}, \mathrm{j}, \mathrm{t} / \mathrm{t}-1$ & & & $\begin{array}{l}0.288^{* *} \\
(0.134)\end{array}$ & $\begin{array}{l}0.513^{* *} \\
(0.217)\end{array}$ \\
\hline Import growth $\mathrm{i}_{\mathrm{j}, \mathrm{j}, \mathrm{t}-\mathrm{t}-\mathrm{t}}$ & $\begin{array}{c}0.116^{*} \\
(0.067)\end{array}$ & $\begin{array}{c}0.114^{*} \\
(0.068)\end{array}$ & $\begin{array}{c}-0.001 \\
(0.087)\end{array}$ & $\begin{array}{c}-0.029 \\
(0.099)\end{array}$ \\
\hline $\ln (\text { Imports) })_{i, j, t-1}$ & $\begin{array}{l}0.624^{* * *} \\
(0.061)\end{array}$ & $\begin{array}{l}0.630^{* * *} \\
(0.064)\end{array}$ & $\begin{array}{c}0.595^{* * *} \\
(0.057)\end{array}$ & $\begin{array}{c}0.597^{* * *} \\
(0.061)\end{array}$ \\
\hline $\ln ($ Real exchange rate $), i, j,-1$ & $\begin{array}{c}0.777^{* * *} \\
(0.133)\end{array}$ & $\begin{array}{l}0.755^{* * *} \\
(0.134)\end{array}$ & $\begin{array}{l}0.741^{* * *} \\
(0.137)\end{array}$ & $\begin{array}{l}0.714^{* * * *} \\
(0.140)\end{array}$ \\
\hline Importer GDP growth ${ }_{i, t / t-3}$ & $\begin{array}{c}-0.608 \\
(0.497)\end{array}$ & $\begin{array}{c}-0.566 \\
(0.500)\end{array}$ & $\begin{array}{c}-0.529 \\
(0.534)\end{array}$ & $\begin{array}{c}-0.461 \\
(0.543)\end{array}$ \\
\hline Exporter GDP growth ${ }_{\mathrm{j}, \mathrm{t} / \mathrm{t}-3}$ & $\begin{array}{c}-0.071 \\
(0.375)\end{array}$ & $\begin{array}{c}-0.090 \\
(0.382)\end{array}$ & $\begin{array}{l}-0.137 \\
(0.382)\end{array}$ & $\begin{array}{c}-0.142 \\
(0.389)\end{array}$ \\
\hline Year FE & Yes & Yes & Yes & Yes \\
\hline Dyad FE & Yes & Yes & Yes & Yes \\
\hline Observations & 9,142 & 9,142 & 9,142 & 9,142 \\
\hline Pseudo $\mathrm{R}^{2}$ & 0.23 & 0.23 & 0.24 & 0.24 \\
\hline
\end{tabular}

Notes: The dependent variable is the count of AD measures introduced by country $i$ against country $j$ in year $t$. PTAs are included in the regressors if they affect at least $5 \%$ of the import volume of the importing country. The table reports the estimated coefficients of negative binomial regressions with standard errors clustered at country-pair level; ***, **, * denote significance at the $1 \%, 5 \%$, and $10 \%$ level, respectively. 
Table 8: Robustness: included country pairs

\begin{tabular}{|c|c|c|c|c|}
\hline & (1) & $\begin{array}{c}(2) \\
\ln (1+X)\end{array}$ & (3) & $\begin{array}{c}(4) \\
\ln (1+X)\end{array}$ \\
\hline PTAs negotiation ${ }_{i, k, t}$ & $\begin{array}{l}-0.113^{*} \\
(0.060)\end{array}$ & $\begin{array}{c}-0.202^{* *} \\
(0.092)\end{array}$ & & \\
\hline PTAs implementedi,k,t & $\begin{array}{c}-0.143^{* *} \\
(0.073)\end{array}$ & $\begin{array}{c}-0.293^{* *} \\
(0.133)\end{array}$ & & \\
\hline FTAs negotiation ${ }_{i, k, t}$ & & & $\begin{array}{l}-0.002 \\
(0.056)\end{array}$ & $\begin{array}{l}-0.020 \\
(0.092)\end{array}$ \\
\hline CUs negotiation & & & $\begin{array}{c}-0.576^{* * *} \\
(0.162)\end{array}$ & $\begin{array}{c}-0.788^{* * *} \\
(0.238)\end{array}$ \\
\hline FTAs implementedi,k,t & & & $\begin{array}{l}-0.166^{* *} \\
(0.080)\end{array}$ & $\begin{array}{c}-0.404^{* * *} \\
(0.146)\end{array}$ \\
\hline FTAs implementedi,k,t x Import growth $\mathrm{h}_{\mathrm{i}, \mathrm{j}, \mathrm{t} t \mathrm{t}-1}$ & & & $\begin{array}{c}0.051 \\
(0.084)\end{array}$ & $\begin{array}{c}0.079 \\
(0.173)\end{array}$ \\
\hline CUs implemented $\mathrm{d}_{\mathrm{i}, \mathrm{k}, \mathrm{t}}$ & & & $\begin{array}{l}-0.159 \\
(0.119)\end{array}$ & $\begin{array}{l}-0.165 \\
(0.217)\end{array}$ \\
\hline CUs implemented $\mathrm{i}_{\mathrm{i}, \mathrm{k}, \mathrm{t}} \mathrm{x}$ Import growth $\mathrm{i}, \mathrm{j}, \mathrm{t} t \mathrm{-1}$ & & & $\begin{array}{c}0.329^{* * * *} \\
(0.111)\end{array}$ & $\begin{array}{c}0.490^{* * *} \\
(0.167)\end{array}$ \\
\hline Import growth $_{\mathrm{i}, \mathrm{j}, \mathrm{t} t-1}$ & $\begin{array}{l}0.131^{* *} \\
(0.064)\end{array}$ & $\begin{array}{l}0.131^{* *} \\
(0.065)\end{array}$ & $\begin{array}{c}0.066 \\
(0.071)\end{array}$ & $\begin{array}{c}0.060 \\
(0.072)\end{array}$ \\
\hline $\ln (\text { Imports })_{\mathrm{i}, \mathrm{j}, \mathrm{t}-1}$ & $\begin{array}{l}0.594^{* * *} \\
(0.064)\end{array}$ & $\begin{array}{l}0.598^{* * * *} \\
(0.064)\end{array}$ & $\begin{array}{l}0.576^{* * *} \\
(0.063)\end{array}$ & $\begin{array}{c}0.576^{* * *} \\
(0.062)\end{array}$ \\
\hline $\ln (\text { Real exchange rate })_{\mathrm{i}, \mathrm{j}, \mathrm{t}-1}$ & $\begin{array}{l}0.725^{* * *} \\
(0.126)\end{array}$ & $\begin{array}{c}0.723^{* * *} \\
(0.126)\end{array}$ & $\begin{array}{c}0.745^{* * *} \\
(0.128)\end{array}$ & $\begin{array}{c}0.739^{* * *} \\
(0.128)\end{array}$ \\
\hline Importer GDP growth $\mathrm{i}_{\mathrm{i}, \mathrm{t} / \mathrm{t}-3}$ & $\begin{array}{l}-0.506 \\
(0.449)\end{array}$ & $\begin{array}{l}-0.537 \\
(0.448)\end{array}$ & $\begin{array}{l}-0.408 \\
(0.478)\end{array}$ & $\begin{array}{l}-0.343 \\
(0.480)\end{array}$ \\
\hline Exporter GDP growth $\mathrm{j}, \mathrm{t} t \mathrm{-3}$ & $\begin{array}{c}0.120 \\
(0.358)\end{array}$ & $\begin{array}{c}0.115 \\
(0.358)\end{array}$ & $\begin{array}{c}0.007 \\
(0.361)\end{array}$ & $\begin{array}{l}-0.011 \\
(0.363)\end{array}$ \\
\hline PTA dummy $y_{i, j, t}$ & $\begin{array}{l}-0.332^{* *} \\
(0.134)\end{array}$ & $\begin{array}{c}-0.327^{* *} \\
(0.133)\end{array}$ & $\begin{array}{l}-0.334^{* *} \\
(0.134)\end{array}$ & $\begin{array}{c}-0.323^{* *} \\
(0.134)\end{array}$ \\
\hline Negotiation dummy $\mathrm{i}_{\mathrm{i}, \mathrm{j}}$ & $\begin{array}{c}0.114 \\
(0.126)\end{array}$ & $\begin{array}{c}0.117 \\
(0.127)\end{array}$ & $\begin{array}{c}0.122 \\
(0.128)\end{array}$ & $\begin{array}{c}0.136 \\
(0.129)\end{array}$ \\
\hline Year FE & Yes & Yes & Yes & Yes \\
\hline Dyad FE & Yes & Yes & Yes & Yes \\
\hline Observations & 11,715 & 11,715 & 11,715 & 11,715 \\
\hline Pseudo R² & 0.23 & 0.23 & 0.23 & 0.23 \\
\hline
\end{tabular}

Notes: The dependent variable is the count of AD measures introduced by country $i$ against country $j$ in year $t$. PTAs are included in the regressors if they affect at least $10 \%$ of the import volume of the importing country. The table reports the estimated coefficients of negative binomial regressions with standard errors clustered at country-pair level; ***, **, * denote significance at the $1 \%, 5 \%$, and $10 \%$ level, respectively. 
Table A1: PTAs included in the analysis when using a 10\% threshold

\begin{tabular}{llcc}
\hline PTA name & \multicolumn{1}{c}{$\begin{array}{c}\text { Importing countries } \\
\text { included in the analysis }\end{array}$} & $\begin{array}{c}\text { Type of } \\
\text { PTA }\end{array}$ & $\begin{array}{c}\text { Still under } \\
\text { negotiation }\end{array}$ \\
\hline ASEAN-Australia-New Zealand & Australia, New Zealand, Indonesia & FTA & no \\
ASEAN-China & China, Indonesia & FTA & no \\
ASEAN-India & Indonesia & FTA & no \\
ASEAN-Japan & Indonesia & FTA & no \\
ASEAN-South Korea & Indonesia & FTA & no \\
Australia-China & Australia & FTA & no \\
China-New Zealand & New Zealand & FTA & no \\
China-South Korea & China, South Korea & FTA & no \\
CUSFTA & Canada, USA & FTA & no \\
EU15 enlargement & EU & CU & no \\
EU25 enlargement & EU & CU & no \\
EU-Canada & Canada & FTA & yes \\
EU-Columbia-Peru-Ecuador & Peru & FTA & no \\
EU-India & India & FTA & yes \\
EU-SADC EPA & South Africa & FTA & no \\
EU-South Africa & South Africa & FTA & no \\
EU-Turkey & Turkey & CU & no \\
Japan-South Korea & South Korea & FTA & yes \\
MERCOSUR & Argentina, Brazil & CU & no \\
NAFTA & Canada, Mexico, USA & FTA & no \\
Peru-China & Peru & FTA & no \\
TTIP & EU, USA & FTA & yes \\
US-Australia & Australia & FTA & no \\
US-Peru & Peru & FTA & no \\
\hline NS- & Thg & &
\end{tabular}

Note: Agreements are classified as still under negotiation based on their status at the end of 2015. 
Table A2: Sample period for included importing countries

\begin{tabular}{lcc}
\hline Country & First year & Last year \\
\hline Argentina & 1989 & 2015 \\
Australia & 1989 & 2015 \\
Brazil & 1988 & 2015 \\
Canada & 1980 & 2015 \\
China & 1997 & 2015 \\
European Union & 1980 & 2015 \\
India & 1992 & 2015 \\
Indonesia & 1996 & 2015 \\
Mexico & 1987 & 2015 \\
New Zealand & 1982 & 2015 \\
Peru & 1992 & 2015 \\
South Africa & 1992 & 2015 \\
South Korea & 1986 & 2015 \\
Turkey & 1989 & 2015 \\
USA & 1980 & 2015 \\
\hline
\end{tabular}

